\title{
Intercomparison of modal and sectional aerosol microphysics representations within the same 3-D global chemical transport model
}

\author{
G. W. Mann ${ }^{1,2}$, K. S. Carslaw ${ }^{2}$, D. A. Ridley ${ }^{3}$, D. V. Spracklen ${ }^{2}$, K. J. Pringle ${ }^{2}$, J. Merikanto ${ }^{4}$, H. Korhonen ${ }^{5}$, \\ J. P. Schwarz ${ }^{6}$, L. A. Lee ${ }^{2}$, P. T. Manktelow ${ }^{2, *}$, M. T. Woodhouse ${ }^{2}$, A. Schmidt ${ }^{2}$, T. J. Breider ${ }^{7}$, K. M. Emmerson ${ }^{2, * *}$, \\ C. L. Reddington ${ }^{2}$, M. P. Chipperfield ${ }^{2}$, and S. J. Pickering ${ }^{2}$ \\ ${ }^{1}$ National Centre for Atmospheric Science, University of Leeds, Leeds, UK \\ ${ }^{2}$ School of Earth and Environment, University of Leeds, Leeds, UK \\ ${ }^{3}$ Dept of Atmospheric Science, Colorado State University, Fort Collins, Colorado, USA \\ ${ }^{4}$ Department of Physics, University of Helsinki, Helsinki, Finland \\ ${ }^{5}$ Finnish Meteorological Institute, Kuopio Unit, Kuopio, Finland \\ ${ }^{6}$ Cooperative Institute for Research in Environmental Sciences, University of Colorado, Boulder, Colorado, USA \\ ${ }^{7}$ School of Engineering and Applied Sciences, Harvard University, Cambridge, MA, USA \\ *now at: Halcrow Group Ltd, Headingley, Leeds, UK \\ ** now at: CSIRO Marine and Atmospheric Research, Aspendale, VIC 3195, Australia
}

Correspondence to: G. W. Mann (g.w.mann@leeds.ac.uk)

Received: 14 December 2011 - Published in Atmos. Chem. Phys. Discuss.: 9 January 2012

Revised: 2 May 2012 - Accepted: 4 May 2012 - Published: 22 May 2012

\begin{abstract}
In the most advanced aerosol-climate models it is common to represent the aerosol particle size distribution in terms of several log-normal modes. This approach, motivated by computational efficiency, makes assumptions about the shape of the particle distribution that may not always capture the properties of global aerosol. Here, a global modal aerosol microphysics module (GLOMAP-mode) is evaluated and improved by comparing against a sectional version (GLOMAP-bin) and observations in the same 3-D global offline chemistry transport model. With both schemes, the model captures the main features of the global particle size distribution, with sub-micron aerosol approximately unimodal in continental regions and bi-modal in marine regions. Initial bin-mode comparisons showed that the current values for two size distribution parameter settings in the modal scheme (mode widths and inter-modal separation sizes) resulted in clear biases compared to the sectional scheme. By adjusting these parameters in the modal scheme, much better agreement is achieved against the bin scheme and observations. Annual mean surface-level mass of sulphate, sea-salt, black carbon (BC) and organic carbon (OC) are within $25 \%$ in the two schemes in nearly all regions.
\end{abstract}

Surface level concentrations of condensation nuclei $(\mathrm{CN})$, cloud condensation nuclei (CCN), surface area density and condensation sink also compare within $25 \%$ in most regions. However, marine $\mathrm{CCN}$ concentrations between $30^{\circ} \mathrm{N}$ and $30^{\circ} \mathrm{S}$ are systematically $25-60 \%$ higher in the modal model, which we attribute to differences in size-resolved particle growth or cloud-processing. Larger differences also exist in regions or seasons dominated by biomass burning and in free-troposphere and high-latitude regions. Indeed, in the free-troposphere, GLOMAP-mode BC is a factor 2-4 higher than GLOMAP-bin, likely due to differences in size-resolved scavenging. Nevertheless, in most parts of the atmosphere, we conclude that bin-mode differences are much less than model-observation differences, although some processes are missing in these runs which may pose a bigger challenge to modal schemes (e.g., boundary layer nucleation and ultrafine sea-spray). The findings here underline the need for a spectrum of complexity in global models, with size-resolved aerosol properties predicted by modal schemes needing to be continually benchmarked and improved against freely evolving sectional schemes and observations. 


\section{Introduction}

Aerosol particles affect the radiative budget of the Earth's atmosphere by scattering and absorbing solar and terrestrial radiation and by modifying the albedo and lifetime of clouds, referred to as the direct and indirect aerosol radiative effects (e.g., Seinfeld and Pandis, 1998). A better understanding of how the atmospheric aerosol has changed since the pre-industrial era is vital to improve the robustness of model predictions of anthropogenic climate change. Successive climate assessment reports (Schimel et al., 1996; Penner et al., 2001; Forster et al., 2007) have continued to classify aerosol radiative forcings as having a low level of scientific understanding and larger uncertainty than forcing from changes in long-lived greenhouse gases. However, Kulmala et al. (2011) show that in recent years, improved representations of aerosol properties and sources is leading to a substantial narrowing of the aerosol forcing uncertainty range.

In-situ observations and process modelling have led to major advances in the understanding of key aerosol processes and how they determine the evolution of the particle size distribution, and hence concentrations of cloud condensation nuclei $(\mathrm{CCN})$. For instance, observations of marine aerosol size distributions (e.g., Hoppel et al., 1994) have shown a clear separation between Aitken and accumulation modes at around $100 \mathrm{~nm}$ dry diameter, most likely due to growth of activated particles via in-cloud aqueous sulphate production. Observations of high number concentrations in the upper troposphere in both marine (e.g., Clarke, 1993) and continental regions (e.g., Hofmann, 1993) combined with modelling of atmospheric transport (e.g., Raes, 1995) have led to an understanding that new particle formation in the free troposphere and subsequent entrainment and mixing into the boundary layer represents a major source of marine $\mathrm{CCN}$ (e.g., Raes et al., 2000; Merikanto et al., 2009). More recently, a wide range of observations (e.g., Kulmala et al., 2004) have shown that, in addition to nucleation in the free troposphere, new particle formation occurs very frequently in the boundary layer in a variety of continental environments.

The majority of general circulation models used to provide estimates of aerosol radiative forcings in the fourth IPCC climate assessment report (Forster et al., 2007) used relatively simple aerosol schemes whereby the main components (sulphate, sea-salt, carbonaceous aerosol and dust) are represented by distinct externally-mixed types with only the mass of each transported, and the particle size distribution prescribed at globally uniform values (e.g., Jones et al., 2001; Reddy et al., 2005). Fixing the size distribution means that any growth process included in the models (for instance aqueous sulphate production in clouds) will increase particle number when it increases mass, potentially causing artefacts in simulated aerosol-cloud interactions.

Since the early 1980s, detailed aerosol dynamics schemes, developed initially in box models, emerged to capture aerosol microphysical processes such as new particle formation, and growth by coagulation and condensation. For instance Gelbard et al. (1980) were among the first to produce a sectional aerosol model whereby the general dynamics equation (GDE) over the continuous size spectrum is reformulated according to a discrete set of size sections or bins. Whitby (1981) developed the computationally cheaper "modal" approach, whereby the continuous GDE is given in terms of integral moments of the size distribution within lognormal modes covering different parts of the particle size range. A variation on these approaches is to apply the method of moments (e.g., McGraw, 1997) which does not require any assumption about distribution function within each bin/mode.

The growing realisation of the importance of aerosol microphysical processes in determining aerosol properties led to the implementation of these more complex aerosol schemes into global models. For instance Adams and Seinfeld (2002) developed a dual moment sectional global aerosol microphysics model and Ghan et al. (2001) and Wilson et al. (2001) implemented two-moment modal schemes into global models. Following these pioneering studies, a new generation of global aerosol microphysics models have now been developed with both sectional (e.g., Spracklen et al., 2005, 2008; Kokkola et al., 2008; Luo and Yu, 2011) and modal schemes (Easter et al., 2004; Stier et al., 2005; Liu et al., 2005; Lauer et al., 2005; Bauer et al., 2008; Mann et al., 2010; Pringle et al., 2010; Vignati et al., 2010). Furthermore, Ghan and Schwarz (2007) explain that international climate modelling groups performing co-ordinated experiments for IPCC assessment reports are developing new climate model versions that include more sophisticated aerosol schemes to improve the fidelity of simulated climate forcings.

Modal approaches continue to be favoured over sectional schemes in global models due to lower computational costs. However, simplifications in the parametrized modal approach (e.g., fixing the standard deviation) can cause biases in simulated process rates and size distributions (e.g., Seigneur et al., 1986; Zhang et al., 1999). In box model studies, Herzog et al. (2004) found that number concentrations and surface area density simulated by a modal scheme are, on average, within $20 \%$ of a similar bin-resolved version, but found differences of $50 \%$ on average for simulated accumulation-mode number concentrations. Kokkola et al. (2009) found larger differences between sectional and modal schemes in volcanically perturbed stratospheric conditions, and explored ways to modify the modal scheme to reduce such biases. Weisenstein et al. (2007) compared modal and sectional aerosol schemes at different size resolutions (20, 40 and 150 bins, 3 and 4 modes) when simulating the background and Pinatubo-enhanced stratospheric aerosol. They reduced bias in their 3-mode scheme compared to the bin scheme by narrowing the prescribed width of the accumulation mode from 1.78 to 1.6. Overall they found only moderate differences between the bin and the improved 
3-mode scheme, with both performing similarly against observations.

Although these studies have demonstrated differences in certain conditions, the extent to which the use of modal schemes in 3-D global models leads to systematic biases in simulated aerosol properties has not yet been established. In this study we compare the two-moment sectional (Spracklen et al., 2005, 2008) and two-moment modal (Mann et al., 2010) versions of the GLObal Model of Aerosol Processes (GLOMAP), known as GLOMAP-bin and GLOMAP-mode, respectively. Trivitayanurak et al. (2008) compared GLOMAP-bin against another two-moment sectional scheme (TOMAS, Adams and Seinfeld, 2002) in different 3-D global models, and found major inter-model differences and discrepancies to observations, but the schemes had different process representations, emission inventories, size assumptions, oxidant fields, clouds and transport. Zhang et al. (2010) compared the results from three different general circulation models, which shared the same two-moment modal aerosol dynamics scheme, finding reasonable agreement between simulated size distributions. Largest differences in particle concentrations were found in the tropics and free troposphere due to differences between model treatments of convective transport and wet deposition, the choice of sulphur chemistry scheme and differences in cloud and precipitation. Bergman et al. (2011) implemented a twomoment sectional aerosol scheme (SALSA, Kokkola et al., 2008) into a general circulation model and compared against the existing two-moment modal scheme (M7, Vignati et al., 2004). They found the sectional model to better reproduce observed size distributions at CCN sizes, with both performing similarly over integral properties. Here, we compare the GLOMAP bin and mode schemes in the same 3-D global offline chemistry transport model (Chipperfield, 2006) with the same process representations and parameter settings, ensuring the intercomparison has the same meteorology, oxidants, clouds and aerosol precursor chemistry.

We quantify bin-mode differences in a wide range of simulated integral particle properties such as total and sizeresolved particle number, speciated mass, $\mathrm{CCN}$ concentrations, surface area density and condensation sink. The main aim of the paper is to compare sectional and modal aerosol schemes, and improve the modal scheme to better compare against the bin scheme. Although a detailed evaluation of the two schemes against observations is out of the scope of this paper, we do compare both models to benchmark global datasets of observed size-resolved number concentrations in marine and continental regions. These reference observational datasets are not intended to indicate which scheme is better in some way, but rather to give a context for the differences between the two schemes. By examining particle size distributions simulated with the two schemes, we also aim to provide constraints for the choices of parameter values in modal schemes to reduce any systematic biases in the parameterized modal approach.
Finally, we note that the GLOMAP-mode scheme has also been implemented (Johnson et al., 2010) in the HadGEM3UKCA composition-climate model (Morgenstern et al., 2009; Telford et al., 2009). By making aerosol properties simulated by the modal scheme compare better to the sectional scheme in the offline transport model, we aim to increase the robustness of simulated aerosol radiative forcings, making simulations in the composition-climate model more reliable.

\section{Model description}

GLOMAP-bin and GLOMAP-mode are comprehensively described in Spracklen et al. (2005) and Mann et al. (2010), respectively. The GLOMAP-bin model used here is the multi-component version (v1a as in Merikanto et al., 2009), and differs from that used in the first papers (e.g., Spracklen et al., 2005; Spracklen et al., 2006) which did not discriminate between different aerosol components (e.g., sulphate, sea-salt, black carbon).

The GLOMAP-mode model here (v6), differs slightly from v5 in Mann et al. (2010), having been updated to more closely follow process formulations in GLOMAP-bin. These changes modify the routines for vapour condensation, nucleation scavenging and aqueous sulphate production, and are described in Appendix A. Both GLOMAP schemes are run within the TOMCAT chemistry transport model (Chipperfield, 2006) using the approach described in Spracklen et al. (2005).

The GLOMAP-bin and GLOMAP-mode runs are at $\approx 2.8 \times 2.8^{\circ}$ horizontal resolution on 31 vertical hybrid sigma-pressure levels from the surface to $10 \mathrm{hPa}$. Monthlymeans from January to December 2000 are used following a spin-up of 3 months from zero initial aerosol. Gas phase and aqueous chemistry are indentical in the runs following that described in Mann et al. (2010). Briefly, gas phase reactions of DMS, $\mathrm{SO}_{2}$ and monoterpenes with $\mathrm{OH}, \mathrm{NO}_{3}$ and $\mathrm{O}_{3}$ are included with a small source of $\mathrm{SO}_{2}$ from COS and $\mathrm{CS}_{2}$. Aqueous phase oxidation of dissolved $\mathrm{SO}_{2}$ is simulated via reaction with $\mathrm{H}_{2} \mathrm{O}_{2}$, which is treated semi-prognostically, being transported, depleted via $\mathrm{SO}_{2}$ and replenished by gasphase $\mathrm{HO}_{2}$ self-reaction up to a background value given by the prescribed 3-D oxidant fields. The ASAD chemical integration software (Carver et al., 1997) is used with identical rate files and gas-phase deposition settings, with tendencies for the transported gas-phase species given by the IMPACT algorithm (Carver and Stott, 2000).

The model runs were driven by identical offline fields of meteorology (6-hourly ECMWF ERA40 re-analyses), cloud fields (monthly climatological low-cloud from ISCCP, Rossow and Schiffer, 1999) and oxidants (6-hourly monthlymeans from a full-chemistry TOMCAT run, Arnold et al., 2005). Gaseous and primary particulate emissions for both models are as described in Mann et al. (2010) including 
DMS, $\mathrm{SO}_{2}, \mathrm{COS}, \mathrm{CS}_{2}$, monoterpenes, primary sulphate, carbonaceous aerosol (speciated to $\mathrm{BC}$ and organic carbon, OC) and sea-salt, mostly following the AEROCOM recommended sources as in Dentener et al. (2006). New particle formation occurs mainly in the free troposphere in the model, with the Kulmala et al. (1998) binary nucleation rate expression used. The non-local closure boundary layer mixing scheme from Holtslag and Boville (1993) and the convection parameterization from Tiedtke (1989) is used, with identical settings for bin and mode runs. This set-up ensures that atmospheric transport, primary aerosol sources from direct emission and secondary sources from gas phase precursor oxidation were equivalent in all simulations. Note however, that, differences (up to $20 \%$ in some marine regions) did arise between the bin and mode simulated gas phase precursors (see Table 6) which we attribute to the schemes using different versions of the host chemistry transport model.

\section{Comparison of simulated particle size distributions}

Figure 1 compares simulated surface-level particle size distributions at three marine and three continental locations for GLOMAP-bin (black) and two GLOMAP-mode runs in June (a-f) and December (g-1). The first GLOMAP-mode run (blue line, "modeI") has modal parameter settings as in Mann et al. (2010) with a standard deviation $(\sigma)$ of 2.0 for the coarse mode and 1.59 for all other modes, and mode-edge radii at 5,50 and $500 \mathrm{~nm}$ as separating nucleation-Aitken, Aitken-accumulation and accumulation-coarse modes, respectively. Note that these mode-edge dry radii determine how primary emissions are mapped onto the modes, and are also the size at which particles are transferred to the adjacent larger mode by mode-merging. The second run (red line, "modeR") has revised modal settings, to improve comparison with the bin scheme, whereby the soluble accumulation mode is set narrower with $\sigma=1.40$ and the accumulationcoarse mode-edge dry radius $\left(r_{3,4}\right)$ is reduced to $250 \mathrm{~nm}$. Figure 2 shows the mode edge diameters for these two configurations of GLOMAP-mode alongside the size interfaces for 20 GLOMAP-bin size sections.

In the three ocean locations (Fig. 1a-c and $\mathrm{g}-\mathrm{i}$ ), the bin and mode schemes capture the general observed features of the marine boundary layer size distribution with sub- $\mu \mathrm{m}$ aerosol bi-modal (Aitken and accumulation) with a third coarse mode from sea-spray (e.g., Raes et al., 2000). During winter (Fig. 1c, g, h), marine size distributions in all three runs show an additional distinct nucleation mode below $10 \mathrm{~nm}$ dry radius indicating some new particle formation may be occurring in marine regions. By contrast, during summer (Fig. 1a, b, i), there are very few particles below $10 \mathrm{~nm}$ dry radius in marine regions (as expected from Raes et al., 2000) and the Aitken mode is generally much weaker than in winter. The winter sub-10 $\mathrm{nm}$ dry radius particles have a fairly flat size distribution in the bin scheme whereas the modal scheme has a much stronger peak at 3 to $5 \mathrm{~nm}$, being forced to follow the prescribed width of the mode. This inconsistency may be indicative of a bias in the modal treatment of the growth of nucleated particles up to CCN sizes.

In both seasons, the three marine locations, in all 3 model runs, show a "Hoppel gap" at about $25-40 \mathrm{~nm}$ dry radius, created by growth of activated particles via in-cloud sulphate production (e.g., Raes, 1995). However, with the original modal settings ( $\sigma_{\text {acc }}=1.59$ and $r_{3,4}=500 \mathrm{~nm}$ ), the minimum in $\mathrm{d} N / \mathrm{d} \log r$ between Aitken and accumulation modes is, compared to bin, biased high in summer in all regions (Fig. 1a, b, i). For this run, the accumulation mode radius is also biased substantially high in winter against the peak in the bin scheme (Fig. 1c, g, h). With these original modal settings, the accumulation mode, is also too wide compared to bin in all 3 locations. By contrast, when $\sigma_{\text {acc }}$ is set to 1.4, and $r_{3,4}$ also reduced to $250 \mathrm{~nm}$, GLOMAP-mode performs much better, with the size of the accumulation-mode peak, and its shift from summer to winter, matching well to the sectional scheme.

Another bias in GLOMAP-mode (with the original settings) is that, in all three marine locations, the coarse mode number is much less than in GLOMAP-bin (by factor 2-3) in both seasons. With the revised settings however, GLOMAPmode compares well, due to the sea-spray emissions then being mapped more coherently onto the lognormal modes. In the sectional scheme, the simulated coarse mode begins at about $300 \mathrm{~nm}$ dry radius with a peak at about $500-600 \mathrm{~nm}$ (Fig. 1). In GLOMAP-mode, the coarse-soluble mode only receives emitted sea-spray larger than $r_{3,4}$, so with this set to $500 \mathrm{~nm}$ the modal approach effectively splits the sea-spray mode in two where there should be a peak, leading to the low bias in coarse mode number. In the revised modal configuration (red line), the split occurs at $250 \mathrm{~nm}$, matching the size of the minimum seen in the size distribution for the freely-evolving sectional scheme. The accumulation mode is also compromised in GLOMAP-mode when $r_{3,4}=500 \mathrm{~nm}$. Since the modal approach has to construct a single lognormal distribution for all particles in a mode, it must combine any sea-spray emitted into the mode with finer sulphate particles. In the $r_{3,4}=500 \mathrm{~nm}$ run, this effect pulls the mode radius to erroneously large sizes. whereas with $r_{3,4}=250 \mathrm{~nm}$, the bias from the effect is greatly reduced since sea-spray particles are then mostly emitted into the soluble coarse mode.

Figure 3 further examines marine particle size distribution, showing the latitudinal variation of Aitken and accumulation mode dry diameter from the two GLOMAP-mode runs against observed values derived from a 30-yr compilation of marine size distribution measurements (Heintzenberg et al., 2000). The observed mean dry diameter values are from 3and 4-mode lognormal fits to the ship-borne mobility and aerodynamic particle sizer measured dry size distributions (below $40 \%$ relative humidity). To compare against these observations, model marine-zonal-mean dry diameter values for each mode were obtained via number-weighted means 

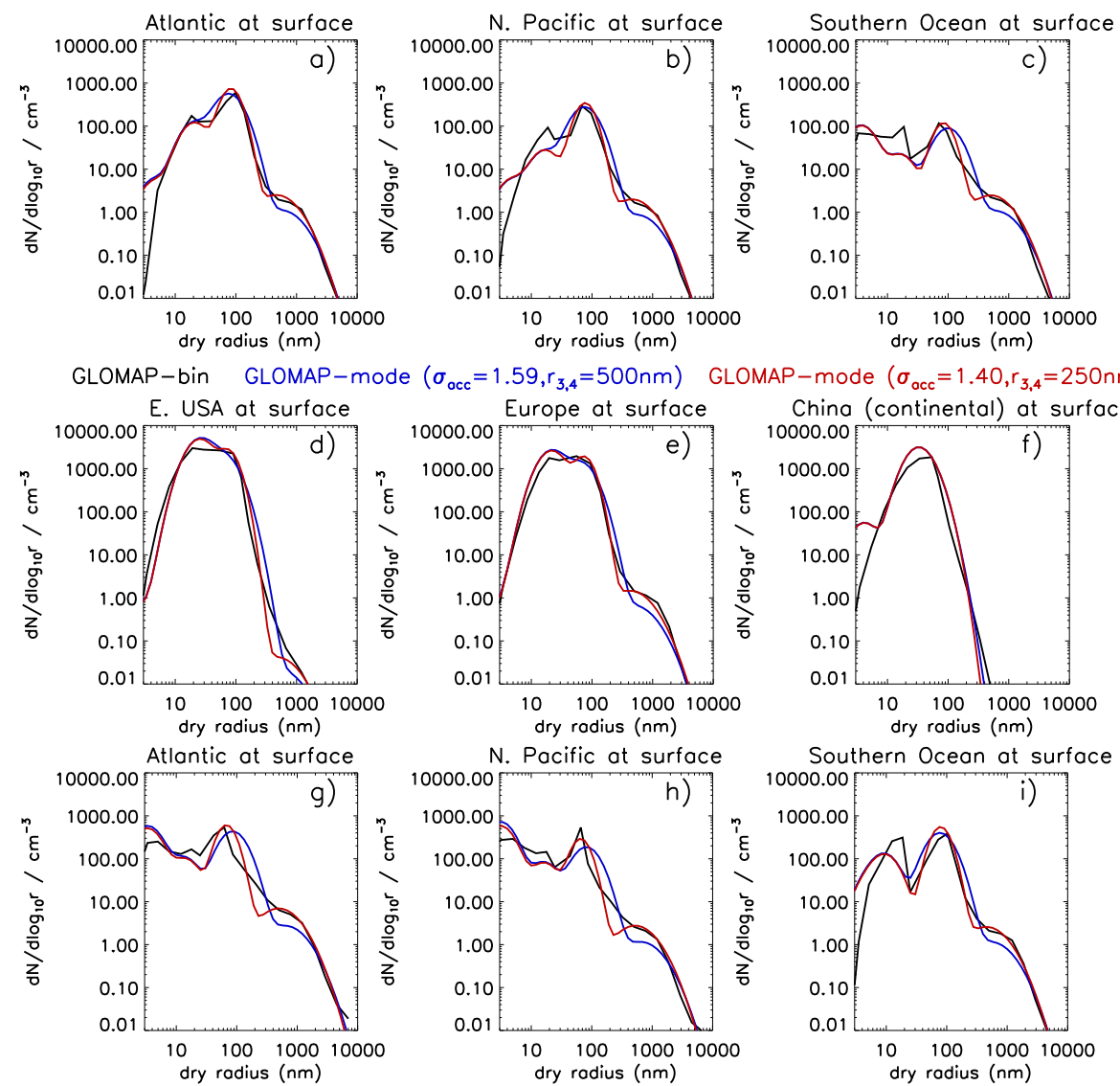

OMAP-mode $\left(\sigma_{\text {occ }}=1.40, r_{3,4}=250 \mathrm{~nm}\right)$
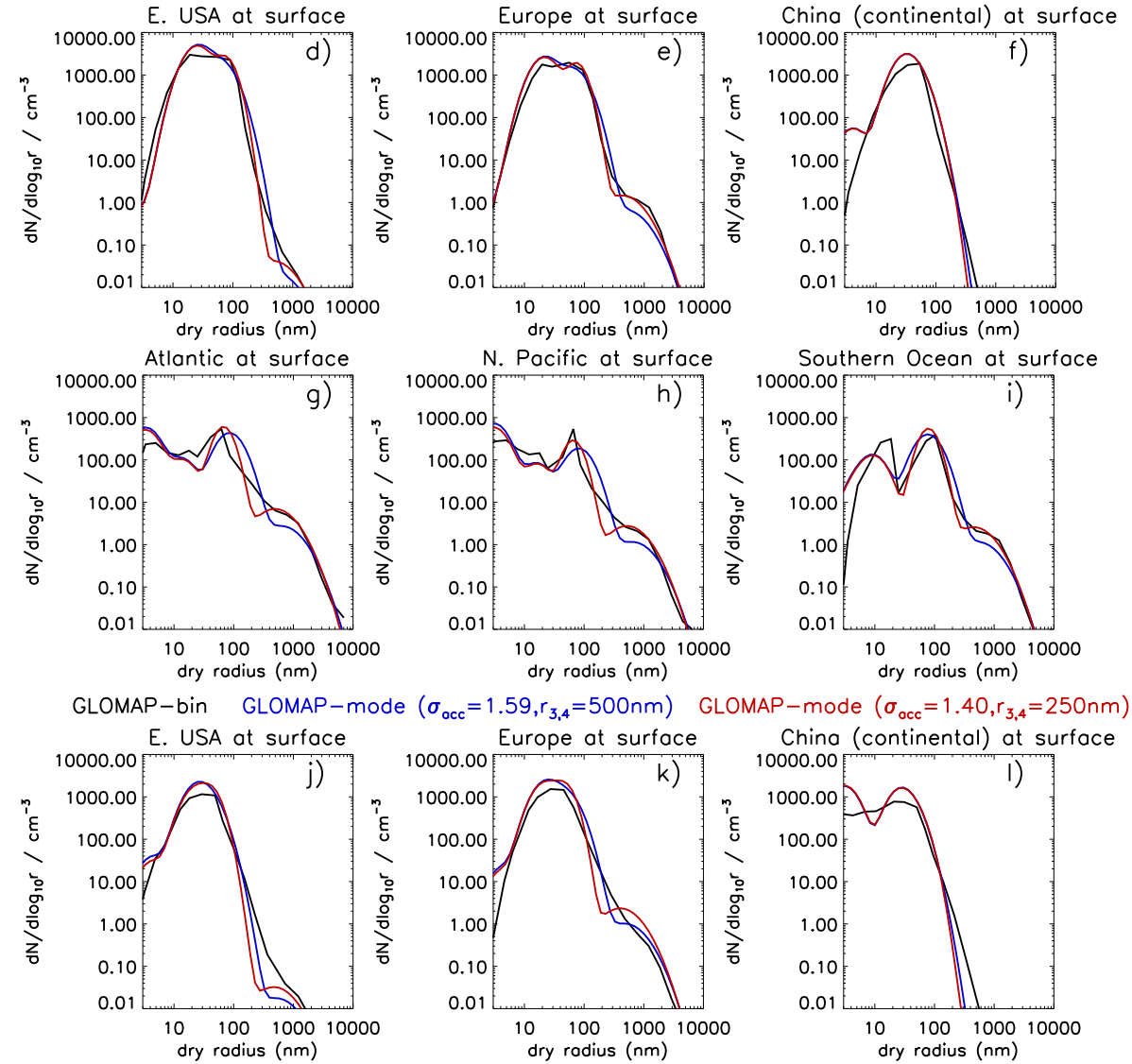

Fig. 1. Surface size distributions simulated by GLOMAP-bin (black) and the standard (v6I) GLOMAP-mode run (blue) and improved (v6R) GLOMAP-mode run (red). Number size distributions $(\mathrm{d} N / d \log r)$ are shown for three marine and three continental locations in June (a-f) and December (g-l) The exact locations are as follows: Atlantic $\left(40^{\circ} \mathrm{W}, 43^{\circ} \mathrm{N}\right)$, N. Pacific $\left(163^{\circ} \mathrm{W}, 43^{\circ} \mathrm{N}\right)$, Southern Ocean $\left(163^{\circ} \mathrm{W}, 38^{\circ} \mathrm{S}\right), \mathrm{E}$. USA $\left(84^{\circ} \mathrm{W}, 43^{\circ} \mathrm{N}\right)$, Europe $\left(6^{\circ} \mathrm{E}, 54^{\circ} \mathrm{N}\right)$ and China $\left(101^{\circ} \mathrm{E}, 35^{\circ} \mathrm{N}\right)$.

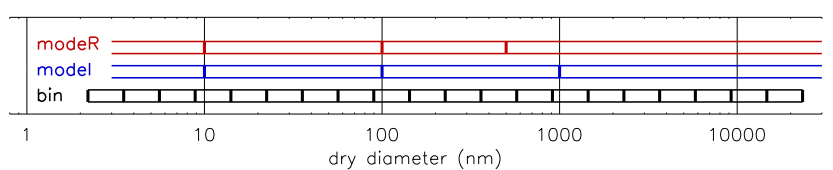

Fig. 2. Schematic diagram showing the mode edge sizes for the original (modeI, blue lines) and revised (modeR, red lines) configurations of GLOMAP-mode. The template size bin interfaces in the moving-centre, fixed-edge GLOMAP-bin sectional approach are also soon (bin, black lines). over all ocean gridboxes on each latitude grid-point, and averaging up to the 15 degree grid in the observations. There is no significant difference in simulated Aitken-mode size or number between the two GLOMAP-mode runs, and good agreement between model and observations, with larger particle size in the tropics compared to mid-latitudes. However, in the accumulation mode, the original GLOMAP-mode settings give too large size in the Southern Ocean (due to the sea-spray effects described above), whereas much better agreement is seen with the revised settings. In the $30^{\circ} \mathrm{S}$ to $50^{\circ} \mathrm{N}$ marine regions, the modal scheme as originally 


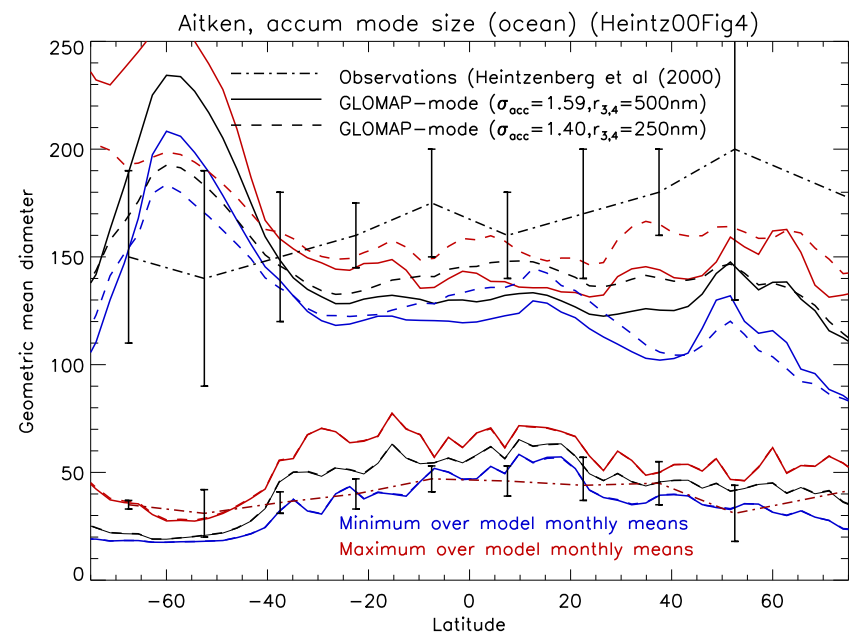

Fig. 3. Simulated marine surface zonal-mean geometric mean particle diameters in the Aitken and accumulation mode compared to observed values from a compilation of 30-yr of measured size distribution data (asterisks) for the marine boundary layer (Heintzenberg et al., 2000). The black lines show simulated annual mean (averaged to the 15-degree grid) and the blue/red lines show minimum/maximum monthly-mean values. Results from two GLOMAP-mode v6 runs are shown: as configured originally (solid lines) and after the revisions to the modal aerosol settings (dashed lines). The error-bars around the asterisks show the observed standard-deviation in each latitude band. Values of normalised mean bias and correlation coefficient are shown in Table 5 from model annual-means (ocean grid boxes only) and by averaging up to the 15 degree grid to match the observations.

configured has a substantial low bias in the simulated size of the accumulation mode compared to the observations which is considerably improved with the reduced values of $\sigma_{\text {acc }}$ and $r_{3,4}$. We attribute this improvement to the narrowing of the width of the accumulation mode, with the original wider setting giving too effective scavenging of the larger sizes, leading to the low bias in geometric mean radius.

In the three continental locations (all in the Northern Hemisphere), sub- $\mu \mathrm{m}$ size distributions in winter (Fig. $1 \mathrm{j}-$ 1) are uni-modal in all three runs, with a peak at about 25 to $35 \mathrm{~nm}$ dry radius. A pronounced accumulation-mode shoulder is evident in summer (Fig. 1d-f) up to about 60$90 \mathrm{~nm}$ dry radius. However, in both GLOMAP-mode runs, the Aitken-mode number peak is substantially biased low compared to bin, particularly in winter, and is also too narrow. The low $\mathrm{d} N / \mathrm{d} \log r$ may indicate deficiencies in the modal treatment of coagulation where rates based on the mode mean radii could be too high. Another possible cause is that primary carbonaceous emissions are sized here to have $\sigma=1.8$ (following Dentener et al., 2006). Whereas the size sections in GLOMAP-bin can adapt freely to this prescribed shape, in GLOMAP-mode, the Aitken mode is forced to be narrower, held fixed at 1.59. This mis-match in $\sigma$ values leads to the bin and mode schemes having different particle num-

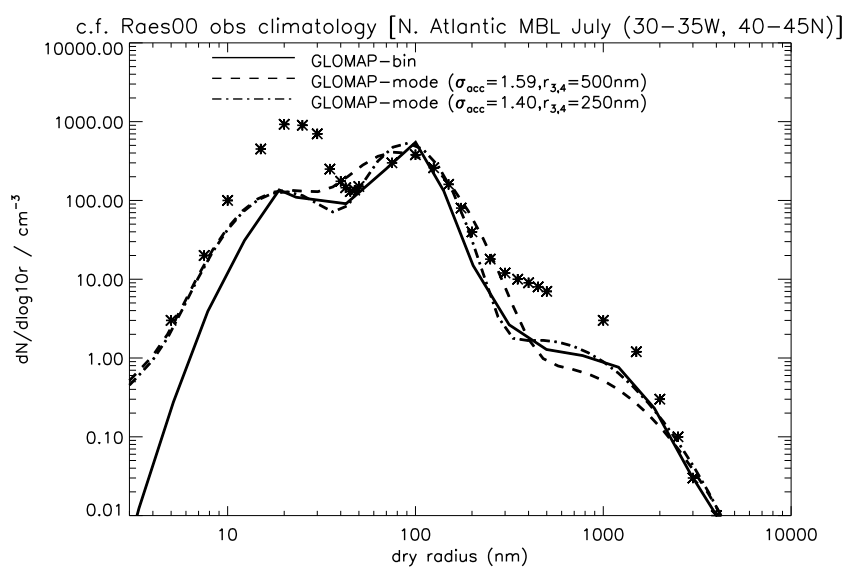

Fig. 4. Surface number size distributions at $\left(30-35^{\circ} \mathrm{W}, 40-\right.$ $45^{\circ} \mathrm{N}$ ) as simulated by GLOMAP-bin (solid), the standard (v6I) GLOMAP-mode run (dashed) and improved (v6R) GLOMAPmode run (dot-dashed). The observations (asterisks) represent the July climatological size distribution reported for clean marine air masses in Raes et al. (2000). Model lines are July means over the range $30-35^{\circ} \mathrm{W}, 40-45^{\circ} \mathrm{N}$.

ber emissions rates even though the mass emission rates and assumed size at emissions are the same.

In the accumulation-mode, GLOMAP-mode compares better to bin than in the Aitken sizes. The size distribution for all three runs shows a similar pronounced shoulder during summer but, again, the original configuration of GLOMAP-mode has the accumulation mode too wide in the large-end tail, whereas much better agreement is achieved with the narrower $\sigma$.

Figure 4 compares against a climatological observed size distribution from Raes et al. (2000) for the marine boundary layer at Tennerife in July, which combines differential mobility analyzer (sub- $\mu \mathrm{m})$ and aerodynamic particle sizer (super- $\mu \mathrm{m})$ measurements. In marine locations, the model size distribution is generally tri-modal (see Fig. 1) with distinct Aitken and accumulation modes separated by a minimum at about $50 \mathrm{~nm}$ dry radius, and a distinct coarse mode at dry-radii larger than $300 \mathrm{~nm}$. Figure 4 shows the July monthly-mean from GLOMAP-bin (solid), GLOMAP-mode as configured originally (dashed) and with the revised modalsettings (dot-dashed). The figure confirms that an accumulation mode $\sigma$ of 1.59 is too wide, with the $\sigma=1.4$ run agreeing better with the shape of the observed accumulationmode. The too wide shape of the original GLOMAP-mode configuration leads to an overestimation in the 50 to $90 \mathrm{~nm}$ dry radius range, although the peak value is better captured for $\sigma=1.59$ in the range 90 to $130 \mathrm{~nm}$. This is just an example comparison in typical background marine boundary layer conditions, and a wider discussion on mode widths in observed size distributions is given in Sect. 7. Comparing the minima/maxima over the 12 monthly-mean size distributions at this site between bin and mode (not shown) also 
suggests that revising the modal settings improves simulated intra-annual variability in size distribution compared to bin.

\section{Comparison of model global burden and budgets}

Here, we examine the global aerosol lifecycle simulated by the bin and mode schemes, with the GLOMAP-mode run using the revised modal settings. Table 2 compares annual-mean global column-integrated mass burdens for each aerosol component (sulphate, sea-salt, BC and particulate organic matter, POM), along with their source mass fluxes from primary emissions and secondary production. Simulated lifetimes and percentage removal by wet deposition are also shown to aid the analysis.

Compared to GLOMAP-bin, simulated sulphate and POM burdens are slightly lower in GLOMAP-mode $(-12$ and $-3 \%)$ whereas BC and sea-salt are slightly higher $(+4$ and $+9 \%)$. These are reflected in the slightly shorter lifetimes for GLOMAP-mode simulated sulphate and POM, while BC and sea-salt are longer-lived with the modal approach. However, for each species, the global burdens compare well, with GLOMAP-mode within about $10 \%$ of GLOMAP-bin. To set these differences in context, we note the findings in Textor et al. (2006), who examined diversity in simulated lifetimes among the AEROCOM models, finding standard deviations among the models of 58, 43, 18, 33 and $27 \%$ for sea-salt, dust, sulphate, BC and POM, respectively. Thus, inter-modal diversity is much larger than the difference introduced by the simplified model treatment of the evolving size distribution. The percentage removal by wet deposition illustrates that wet removal is the dominant removal process for sulphate, $\mathrm{BC}$ and POM, which reside mainly in sub- $\mu \mathrm{m}$ particle sizes, whereas the coarser sea-salt aerosol is influenced strongly by sedimentation. While the bin and mode schemes predict similar wet removal for sulphate, BC and POM, there is a substantial difference for sea-salt, with $27.1 \%$ of mass removal by wet deposition in GLOMAP-mode compared to $47.1 \%$ in GLOMAP-bin. This suggests that the wet removal is acting on a larger proportion of the sea-salt particles in GLOMAPbin than GLOMAP-mode, likely due to more highly sizeresolved treatment possible in the sectional scheme, giving different removal timescales for each size bin.

\section{Comparison of global distributions of integral aerosol properties}

In this section, we examine differences in the global distribution of aerosol properties between the bin and mode schemes. The first sub-section assesses regional differences in surface concentrations of condensation nuclei $(\mathrm{CN}$, all particles with $\left.D_{\mathrm{p}}>10 \mathrm{~nm}\right)$, cloud condensation nuclei $\left(\mathrm{CCN}_{50}\right.$, soluble particles with $D_{\mathrm{p}}>50 \mathrm{~nm}$ ) and $\mathrm{N}_{150}$ (all particles with $D_{\mathrm{p}}>150 \mathrm{~nm}$ ), showing how the narrower soluble accumulation mode width $\left(\sigma_{\mathrm{acc}}\right)$ and reduced accumulation-coarse mode edge radius $\left(r_{3,4}\right)$ improves predictions with the modal scheme. The other sub-sections then compare bin and mode simulated global surface level distributions of a range of integral aerosol properties, with the GLOMAP-mode run using the revised modal settings.

\subsection{Comparison of regional $\mathrm{CN}$ and $\mathrm{CCN}$ concentration}

Table 1 shows the impact of the changes to the mode-edge radius and standard deviation on bin-mode differences in regional mean concentrations of $\mathrm{CN}, \mathrm{CCN}_{50}$ and $\mathrm{N}_{150}$ for the regions used in Merikanto et al. (2009).

The revisions to $\sigma_{\text {acc }}$ and $r_{3,4}$ have only a minor effect on GLOMAP-mode simulated $\mathrm{CN}$ and $\mathrm{CCN}_{50}$, although in each of the regions, the 10-15\% high bias compared to bin is reduced slightly. However, simulated $\mathrm{N}_{150}$ are substantially too low with the original modal settings, with the low bias compared to bin in the range 33-45\% in Europe, North America, North Asia, South East Asia and Oceania. On the global continental average, the modal scheme, as originally configured is $40 \%$ lower than bin, reflecting the biases in particles with $D_{\mathrm{p}}>100 \mathrm{~nm}$ seen in Fig. $1 \mathrm{~d}-\mathrm{f}, \mathrm{j}-1$. With the revisions to the modal settings, $\mathrm{N}_{150}$ agrees better with the bin scheme, with the low bias reduced in all regions, although still at $23 \%$ on the global continental average.

\subsection{Speciated particle mass}

Figure 5 compares surface-level mass concentrations of sulphate $(a, b)$ and sea-salt $(c, d)$. Over the vast majority of the domain, GLOMAP-mode sulphate is within $25 \%$ of GLOMAP-bin (Fig. 5b), with a weak low bias. In the Arctic and parts of the Southern Ocean, Central Africa and South America, the low bias is larger, but never exceeds a factor of two. The regions with lower sulphate in GLOMAPmode also show a similar magnitude $\mathrm{SO}_{2}$ low bias compared to GLOMAP-bin (not shown), which suggests that the different CTM version used (see Sect. 2) may be causing some of this bin-mode difference. In high altitude surface regions (e.g., the Himalayas, Canadian Rocky Mountains) however, GLOMAP-mode sulphate is biased low compared to GLOMAP-bin whereas $\mathrm{SO}_{2}$ is not. In the tropics and sub-tropics, GLOMAP-mode simulated sulphate in the free troposphere is lower than GLOMAP-bin (not shown). The low bias is largest between 3 and $6 \mathrm{~km}$ where rainout has a dominant influence on aerosol properties, suggesting that different size-resolved scavenging may be the cause. Rasch et al. (2000) showed that sulphate mixing ratios in the free troposphere vary by a factor $2-5$ due to differences in convective transport and removal processes.

Simulated surface sea-salt mass is compared in Fig. 5d. In most marine regions the two schemes compare within $25 \%$, although in the Southern Ocean and off the west coast of South America and South Africa, GLOMAP-bin sea-salt mass is systemically higher than in GLOMAP-mode by up to 
a)

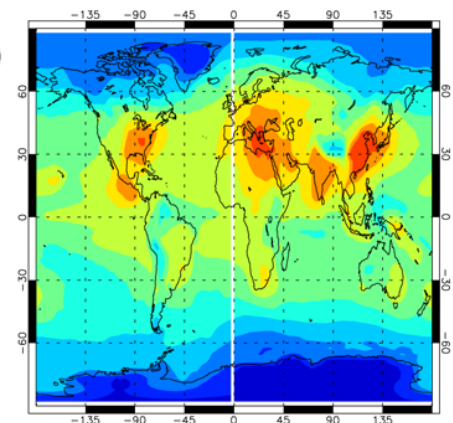

c)

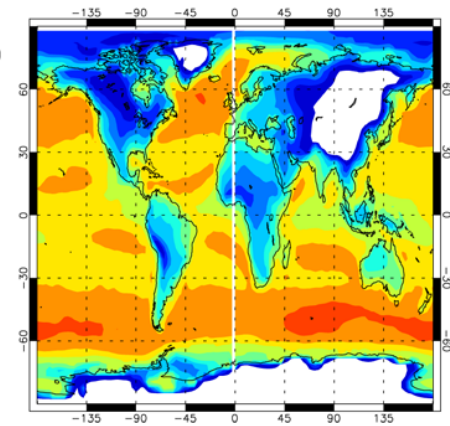

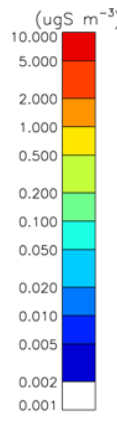

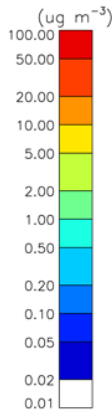

b)
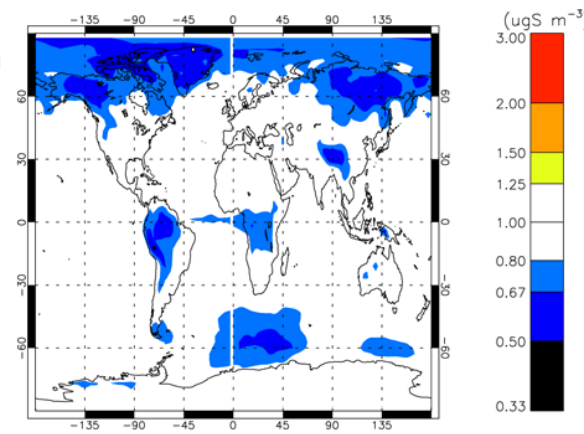

d)
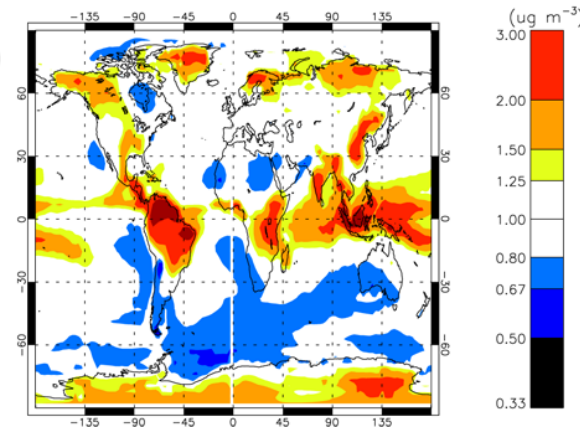

Fig. 5. Global surface maps showing (a) sulphate $\left(\mathrm{SO}_{4}\right)$ and (c) sea-salt $(\mathrm{NaCl})$ aerosol mass simulated by GLOMAP-mode (v6R) on the annual-mean. The ratio of GLOMAP-mode (v6R) to GLOMAP-bin simulated $\mathrm{SO}_{4}$ and $\mathrm{NaCl}$ are shown in panels (b, d), respectively. Regions coloured yellow, orange and red in the relative bias maps indicate where GLOMAP-mode is higher than bin by 25-50, 50-100 and $100-200 \%$, respectively, whilst light-blue, dark-blue and black indicate where bin is higher by the same proportions. Regions where the two schemes are within $25 \%$ are colored white.

a)

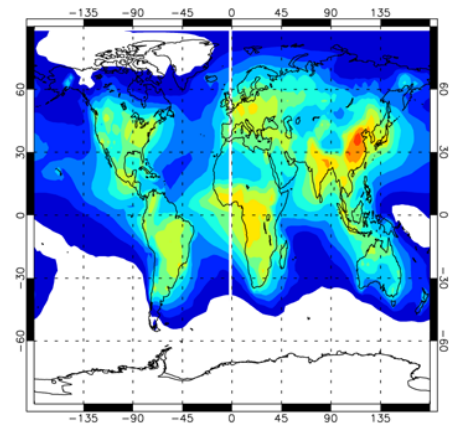

c)

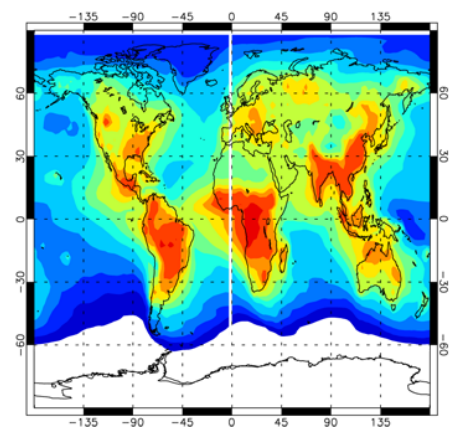

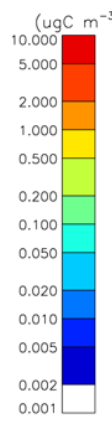

b)
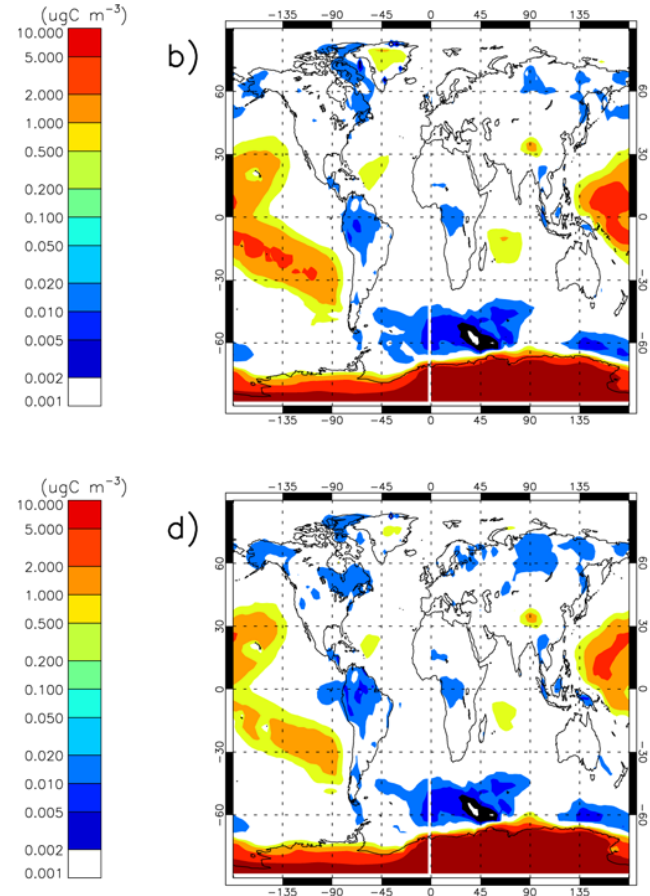

d)

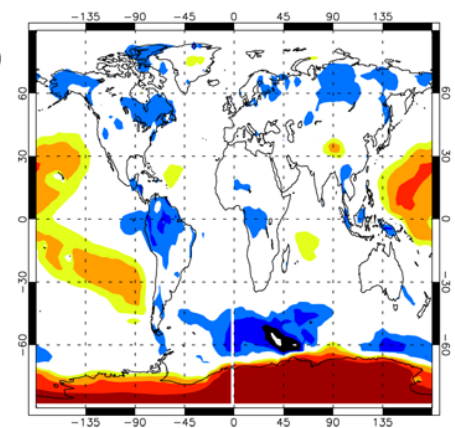

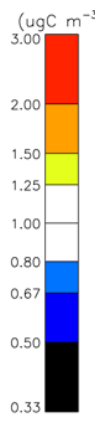

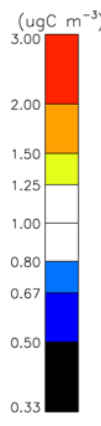

Fig. 6. Global surface maps showing (a) BC and (c) OC aerosol mass simulated by GLOMAP-mode (v6R) on the annual-mean. The ratio of GLOMAP-mode (v6R) to GLOMAP-bin simulated BC and OC are shown in panels (b, d), respectively. Regions coloured yellow, orange and red in the relative bias maps indicate where GLOMAP-mode is higher than bin by 25-50, 50-100 and 100-200\%, respectively, whilst light-blue, dark-blue and black indicate where bin is higher by the same proportions. Regions where the two schemes are within $25 \%$ are colored white. 
Table 1. Regional-mean annual-mean $\mathrm{CN}$ (all particles with $D_{\mathrm{p}}>10 \mathrm{~nm}$ ), $\mathrm{CCN}_{50}$ and $\mathrm{N}_{150}$. GLOMAP-bin values are shown first with the ratio of mode/bin shown in parentheses (original modal settings followed by revised). Regions match those defined in Merikanto et al. (2009).

\begin{tabular}{lccc}
\hline Region & $\mathrm{CN}$ & $\mathrm{CCN}_{50}$ & $\mathrm{~N}_{150}$ \\
\hline Global & $693.0(1.12,1.11)$ & $452.1(1.20,1.18)$ & $159.3(0.74,0.87)$ \\
Global Continental & $1519.0(1.14,1.13)$ & $1014.9(1.16,1.14)$ & $308.2(0.60,0.77)$ \\
Global Marine & $371.0(1.08,1.07)$ & $233.4(1.27,1.25)$ & $101.5(0.90,0.99)$ \\
\hline Europe & $3209.0(1.13,1.12)$ & $1657.4(1.14,1.13)$ & $457.7(0.67,0.84)$ \\
Africa & $1289.0(1.18,1.18)$ & $1050.7(1.17,1.16)$ & $387.3(0.62,0.82)$ \\
N. America & $1680.0(1.12,1.11)$ & $1074.0(1.18,1.16)$ & $363.2(0.57,0.75)$ \\
S. America & $1456.0(1.09,1.08)$ & $1224.8(1.13,1.12)$ & $309.9(0.55,0.71)$ \\
N. Asia & $808.0(1.10,1.08)$ & $497.4(1.15,1.11)$ & $163.0(0.63,0.78)$ \\
S.E. Asia & $4027.0(1.17,1.16)$ & $2364.9(1.16,1.14)$ & $631.1(0.58,0.76)$ \\
Oceana & $1078.0(1.08,1.07)$ & $885.3(1.13,1.11)$ & $272.1(0.55,0.70)$ \\
\hline W. of N. America & $396.0(1.09,1.08)$ & $241.7(1.42,1.41)$ & $83.2(0.98,0.97)$ \\
W. of S. America & $232.0(1.09,1.09)$ & $127.0(1.60,1.60)$ & $60.3(1.08,1.09)$ \\
W. of N. Africa & $390.0(1.05,1.04)$ & $240.0(1.31,1.29)$ & $116.5(0.89,0.99)$ \\
W. of S. Africa & $392.0(1.14,1.11)$ & $314.1(1.30,1.27)$ & $163.1(0.94,1.09)$ \\
E. of N.E. Asia & $1268.0(1.10,1.08)$ & $798.5(1.15,1.11)$ & $269.7(0.77,0.92)$ \\
\hline
\end{tabular}

Table 2. Annual mean global mass burden ( $\mathrm{Tg}$ ), emission fluxes, secondary production fluxes (both $\mathrm{Tg} \mathrm{yr}^{-1}$ ) and lifetime (days) for each simulated aerosol component. Also shown is the \% removal by wet deposition for each component. The values for the mode and bin versions of GLOMAP are shown before and after the comma, respectively. Values in parentheses are the median values simulated by AEROCOM models as documented in Textor et al. (2006).

\begin{tabular}{lccccc}
\hline Species & Burden & Primary emission & Production & Lifetime & \% loss by wdep \\
\hline Sulphate & $0.51,0.58(0.66)$ & $1.74,1.72(59.6)$ & $48.5,46.3$ & $3.71,4.44(4.1)$ & $87.5,86.0(88.5)$ \\
Sea-salt & $3.39,3.11(6.39)$ & $2806,2806(6280)$ & $0.0,0.0$ & $0.44,0.40(0.4)$ & $27.1,47.1(30.3)$ \\
BC & $0.100,0.096(0.21)$ & $7.72,7.78(11.3)$ & $0.0,0.0$ & $4.76,4.51(6.5)$ & $79.5,81.5(79.5)$ \\
POM & $0.87,0.90(1.21)$ & $47.0,47.3(69.9)$ & $26.0,25.9$ & $4.59,4.70(6.1)$ & $84.1,85.4(78.9)$ \\
\hline
\end{tabular}

$50 \%$. By contrast, in the Inter-Tropical Convergence Zone, where wet removal dominates, and also in some continental regions, sea-salt is higher in GLOMAP-mode.

In Sect. 4, we found that wet deposition accounts for a much larger fraction of sea-salt removal in GLOMAP-bin, which is consistent with higher sea-salt concentrations for GLOMAP-mode in regions dominated by wet deposition. The global sea-salt burden was slightly higher in GLOMAPmode, which is consistent with the boundary layer being deeper between $30^{\circ} \mathrm{S}$ and $30^{\circ} \mathrm{N}$ (where GLOMAP-mode has higher sea-salt) than at mid-latitudes (where the modal scheme is lower).

Simulated surface BC and OC are compared in Fig. 6. Both components of the carbonaceous aerosol show very similar distributions in bin and mode, with concentrations being within $+25 /-20 \%$ in most regions, although a larger low bias for GLOMAP-mode compared to GLOMAP-bin is evident in equatorial parts of Africa and South America. These regions also show similar magnitude differences in $\mathrm{SO}_{2}$ and sulphate (see Table 6), suggesting that the different CTM version may be responsible for much of this discrepancy.
Comparing the simulated zonal-mean $\mathrm{BC}$ and $\mathrm{OC}$ against latitude and altitude shows that although in the lowest few km the two schemes compare well, above 3-4 km, GLOMAPmode BC and OC both become substantially higher than GLOMAP-bin, by up to a factor 5 in some places. One can even see evidence of this at the surface in Fig. $6 \mathrm{~b}$ and $\mathrm{d}$ with GLOMAP-mode systematically higher in marine regions between $30^{\circ} \mathrm{N}$ and $30^{\circ} \mathrm{S}$, where free tropospheric air is entrained into the boundary layer due to the descending parts of the Hadley and Walker circulations (e.g., Raes et al., 2000).

Figure 7 compares GLOMAP-mode and GLOMAP-bin simulated remote BC profiles against a January 2009 multiflight climatology (Schwarz et al., 2010) of aircraft measurements with the SP-2 instrument (Schwarz et al., 2008) from the HIPPO campaign. The model January-mean was averaged over the latitude and longitude range of the observations, which cover an altitude range of $300 \mathrm{~m}-14 \mathrm{~km}$ and span the latitudes $67^{\circ} \mathrm{S}-80^{\circ} \mathrm{N}$. In the tropics, in common with the AEROCOM models, both schemes over-estimate free troposphere BC by a factor 20-100 compared to the observations, most likely due to poor treatment of convective 

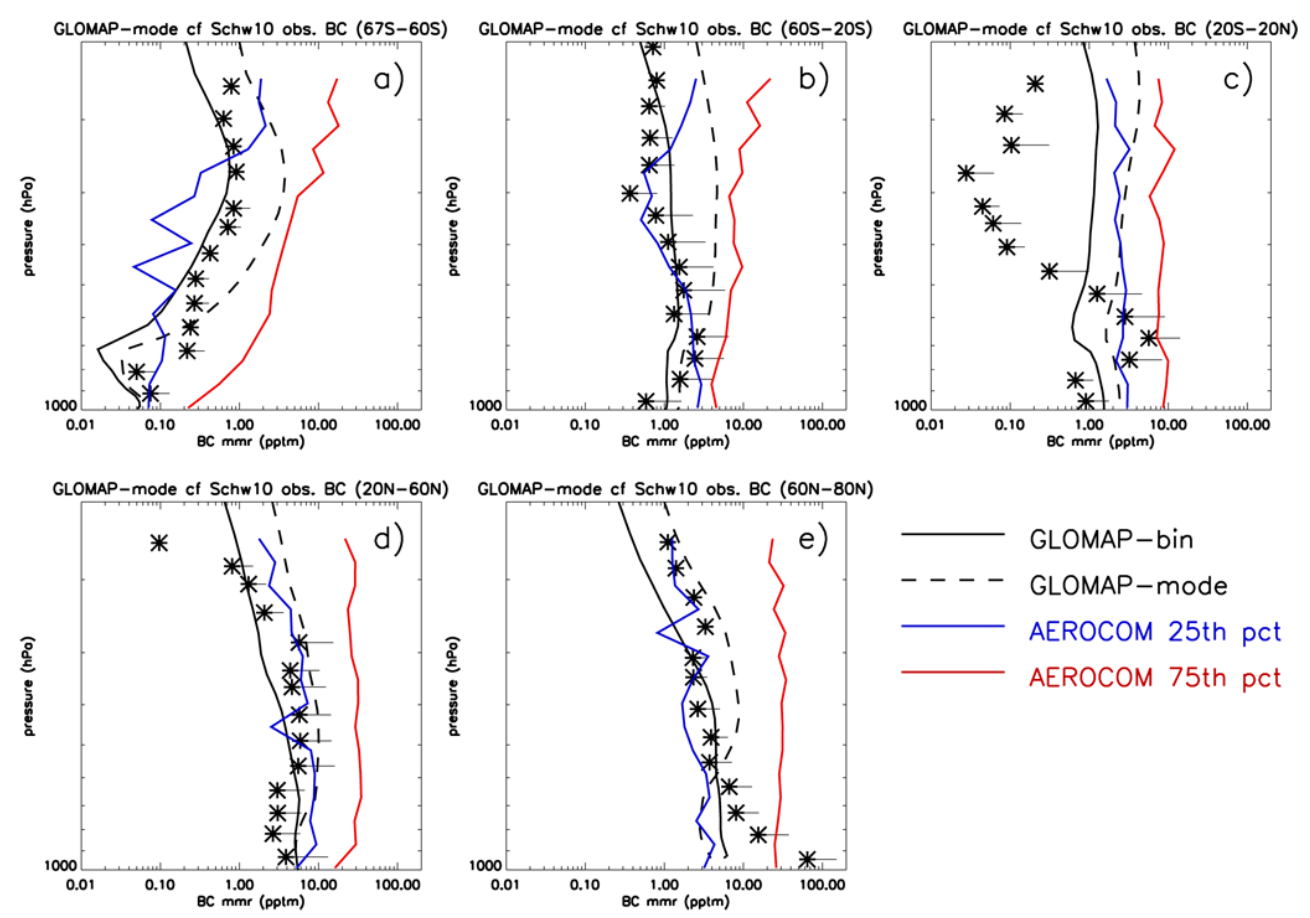

Fig. 7. Vertical profiles of simulated BC mass mixing ratio for GLOMAP-bin (solid) and GLOMAP-mode v6R (dashed) against aircraft SP2 observations (asterisks) from Schwarz et al. (2010). The whiskers on the observations show the standard deviation over the measurements in each $1-\mathrm{km}$ bin. The blue and red lines show the 25 th and 75 th percentiles from models participating in AEROCOM phase 1.

scavenging. In mid- and high-latitudes however, whereas GLOMAP-bin represents the free-tropospheric BC concentrations rather well, GLOMAP-mode is biased high by a factor 2-3 in the Northern Hemisphere and by a factor 3-4 in the Southern Hemisphere. The bin-mode differences are about half the magnitude of the differences between the AEROCOM 15th and 85th percentile profiles, so here the simplification of the size distribution does seem to be a substantial source of bias. These bin-mode differences likely result mainly from size-resolved wet removal being more effective in the bin scheme.

\subsection{Surface sulphuric acid vapour and $\mathrm{CN}$ concentrations}

Figure $8 \mathrm{a}, \mathrm{b}$ show the comparison of surface $\mathrm{H}_{2} \mathrm{SO}_{4}$ concentrations, which is a key factor determining simulated nucleation rates. In general, lower $\mathrm{H}_{2} \mathrm{SO}_{4}$ vapour concentrations are found in GLOMAP-mode, but the two schemes compare quite well, being mostly within $\pm 25 \%$. Differences are larger in some regions however, up to a factor of two in the most polluted regions of China. Removal of $\mathrm{H}_{2} \mathrm{SO}_{4}$ occurs almost exclusively by condensation onto existing aerosol, and the lack of a bias suggests that, although it is not included in these runs, boundary layer nucleation rates (parameterized generally as a function of sulphuric acid concentration, e.g., Spracklen et al., 2010) may not be greatly affected by the simplifications in the modal scheme. How- ever, we note that simpler size-resolved growth in the parameterized modal approach could lead to different condensation sink and cause subsequent biases when boundary layer nucleation is included.

Figure $8 \mathrm{c}, \mathrm{d}$ show that surface $\mathrm{CN}$ concentrations $\left(D_{\mathrm{p}}>\right.$ $10 \mathrm{~nm}$ ) compare very well between GLOMAP-mode and GLOMAP-bin, being within $25 \%$ almost everywhere. Similar agreement is also seen (not shown) for ultrafine $\mathrm{CN}$ $\left(D_{\mathrm{p}}>3 \mathrm{~nm}\right.$ ) although a high bias (up to a factor of 2 ) in the modal scheme is seen in a few very remote regions (Antarctica, the Himalayas and Greenland) where the surface layer in the model is at high altitude.

\subsection{CCN concentrations and vertical extent of biases}

Comparing $\mathrm{CCN}$ in the bin and mode schemes gives an indication of how much the deficiencies in simulated size distribution seen in Sect. 3 are likely to propagate into errors in simulated aerosol-cloud interactions. In Fig. 9, we compare $\mathrm{CCN}$ concentrations based on dry-diameter thresholds of $50 \mathrm{~nm}$ (panels a and b) and $70 \mathrm{~nm}$ (panels c and d). These threshold sizes correspond to supersaturations of 0.35 and $0.22 \%$, respectively, representing values typical for marine stratocumulus, which have the largest spatial coverage and thus dominate aerosol indirect effects globally. Note that here, model $\mathrm{CCN}$ are counted as particles in the soluble modes/distribution larger than the stated dry diameter threshold. 
a)

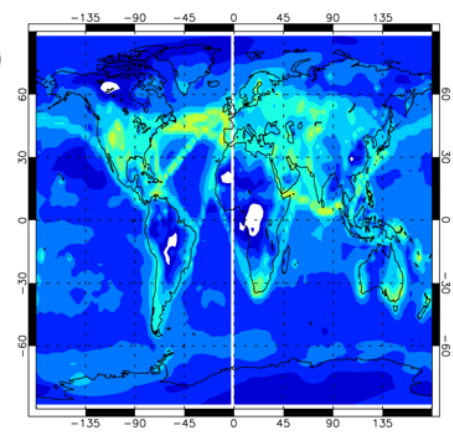

c)

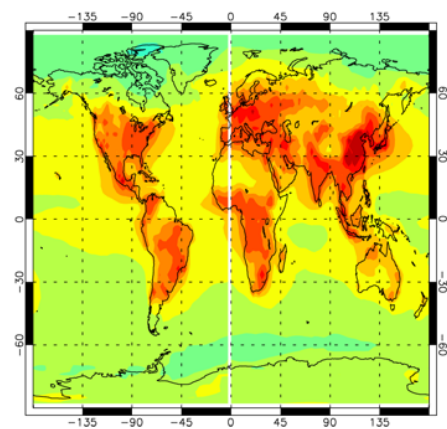

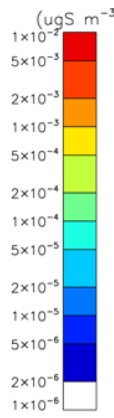

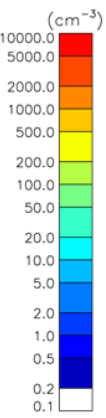

b)
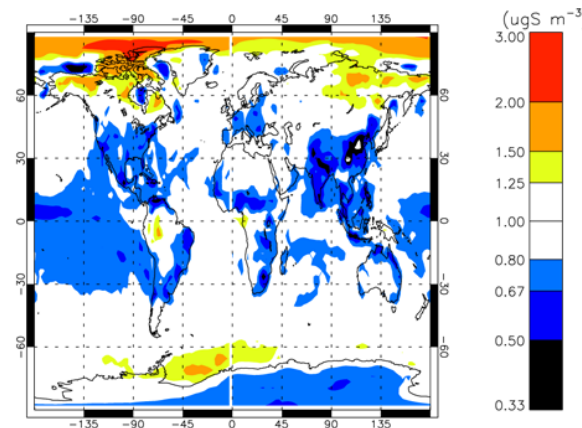

d)
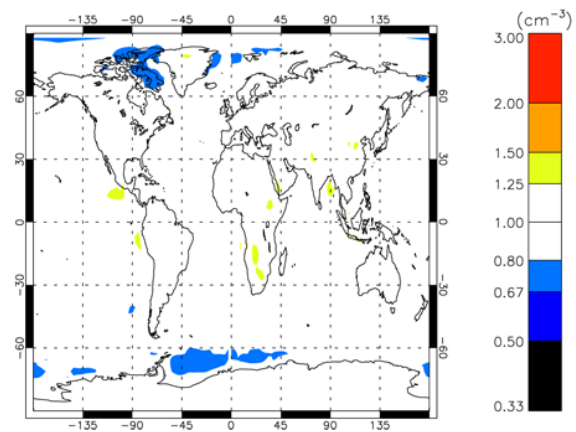

Fig. 8. Global surface maps showing (a) gas phase $\mathrm{H}_{2} \mathrm{SO}_{4}$ and (c) $\mathrm{CN}$ (dry-diameter $>10 \mathrm{~nm}$ ) concentrations simulated by GLOMAP-mode (v6R) on the annual-mean. The ratio of GLOMAP-mode (v6R) to GLOMAP-bin simulated $\mathrm{H}_{2} \mathrm{SO}_{4}$ and $\mathrm{CN}$ concentrations are shown in panels (b, d), respectively. Regions coloured yellow, orange and red in the relative bias maps indicate where GLOMAP-mode is higher than bin by $25-50,50-100$ and 100-200\%, respectively, whilst light-blue, dark-blue and black indicate where bin is higher by the same proportions. Regions where the two schemes are within $25 \%$ are colored white.

In all continental regions, where primary particles dominate CCN (Merikanto et al., 2009), bin and mode CCN concentrations compare well (within $25 \%$ on the annual-mean) at both supersaturations. This level of agreement extends to mid- and high-latitude marine regions, but in the $30^{\circ} \mathrm{S}-$ $30^{\circ} \mathrm{N}$ marine regions, a systematic bias is apparent, with GLOMAP-mode CCN higher by up to $60 \%$.

Figure 10 indicates the vertical extent of these differences, showing zonal-mean CN (all particles with $D_{\mathrm{p}}>10 \mathrm{~nm}$ ) and CCN (soluble particles with $D_{\mathrm{p}}>50 \mathrm{~nm}, \mathrm{CCN}_{50}$ ) against latitude and altitude. Figure 10a shows the expected vertical profile in $\mathrm{CN}$ concentrations with a maximum in the upper troposphere caused by the source of nucleated particles being most efficient there. It is interesting to note that the $D_{\mathrm{p}}>10 \mathrm{~nm}$ particles have maximum concentration in the sub-tropical free troposphere at 8 to $12 \mathrm{~km}$, whereas the equivalent plot for ultrafine $\mathrm{CN}$ (all particles with $D_{\mathrm{p}}>$ $3 \mathrm{~nm}$ ) has maximum concentrations in the tropics between 12 and $17 \mathrm{~km}$, indicating the atmospheric transport and growth of secondary particles. The shape of the $\mathrm{CCN}_{50}$ plot reflects the lifting of primary aerosol in the tropics and transport to higher altitudes in the free troposphere, with mixing of secondary, nucleated aerosol that have grown up to CCN sizes.

One potential source of bias for the parameterized modal aerosol dynamics identified in previous studies (e.g., Zhang et al., 1999) is in coagulation rates predicted when the stan- dard deviation of each mode is held fixed. Coagulation acts to reduce the number concentration of the finest particles in the high-CN nucleation layer. Rates of coagulation depend strongly on particle diameter, and the monodisperse modal treament in GLOMAP-mode could introduce biases by using the geometric-mean diameter as a representative size for the mode in this process. Such biases would affect growth of $\mathrm{CN}$ to larger sizes, which could lead to $\mathrm{CCN}$ biases in the model. However, Fig. 10b shows that the $\mathrm{CN}$ bias is actually below $25 \%$ throughout most of the lowest $10 \mathrm{~km}$ (although larger in the upper troposphere), suggesting the bias caused by this artefact may only be modest.

Figure 10d shows that the surface high bias in GLOMAPmode marine $\mathrm{CCN}$ concentrations between $30^{\circ} \mathrm{S}$ and $30^{\circ} \mathrm{N}$ extends at a similar magnitude and latitudinal extent into the free troposphere, with the bias increasing slightly above $3 \mathrm{~km}$. The spatial pattern of the GLOMAP-mode CCN high bias seen in Fig. 9b and d matches where growth by cloudprocessing is occuring most in the model. The modal treatment of cloud processing involves particles in the largeend of the Aitken-soluble mode being transferred over to the accumulation-soluble mode, with the two modes subsequently re-constructed to give a lognormal shape. It is possible that the $\mathrm{CCN}$ high bias may be partly caused by this simplification, although it may just be reflecting differences in size-resolved growth via condensation or coagulation. 
a)

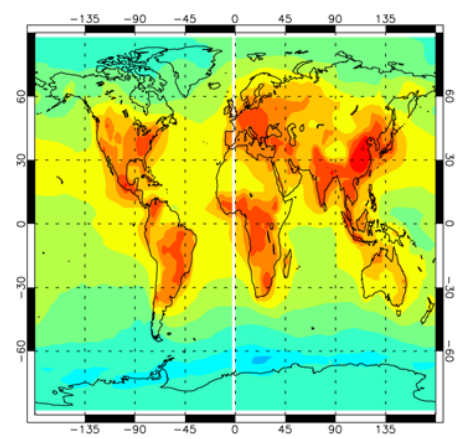

c)

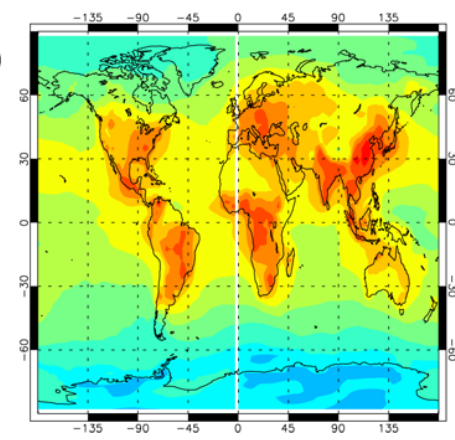

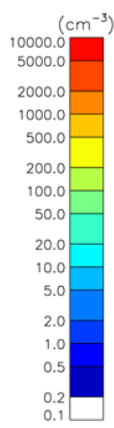

b)
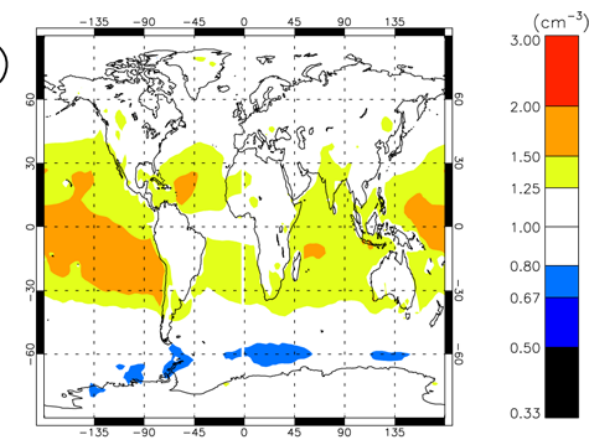

d)
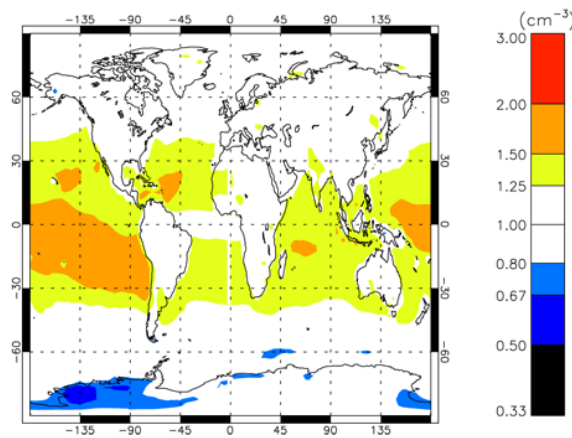

Fig. 9. Global surface maps showing $\mathrm{CCN}$ concentrations for (a) dry diameter $>50 \mathrm{~nm}\left(\mathrm{CCN}_{50}\right)$ and (c) dry diameter $>70 \mathrm{~nm}\left(\mathrm{CCN}_{70}\right)$, as simulated by GLOMAP-mode (v6R) on the annual-mean. The ratio of GLOMAP-mode (v6R) to GLOMAP-bin simulated $\mathrm{CCN}_{50}$ and $\mathrm{CCN}_{70}$ are shown in panels $(\mathbf{b}, \mathbf{d})$, respectively. Regions coloured yellow, orange and red in the relative bias maps indicate where GLOMAPmode is higher than bin by $25-50,50-100$ and $100-200 \%$, respectively, whilst light-blue, dark-blue and black indicate where bin is higher by the same proportions. Regions where the two schemes are within $25 \%$ are colored white.

a)

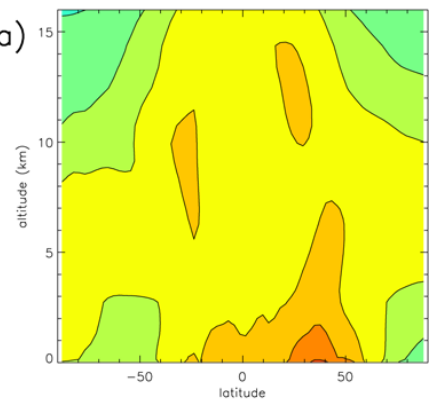

c)

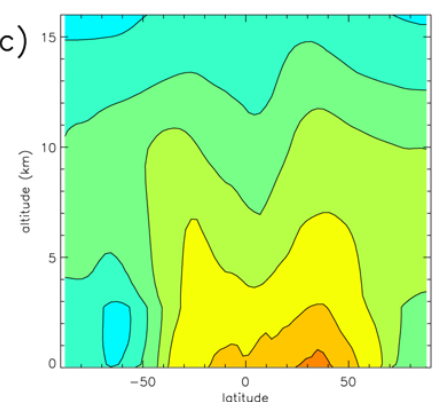

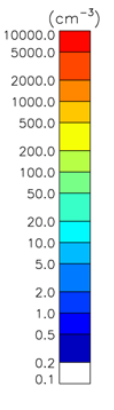

b)
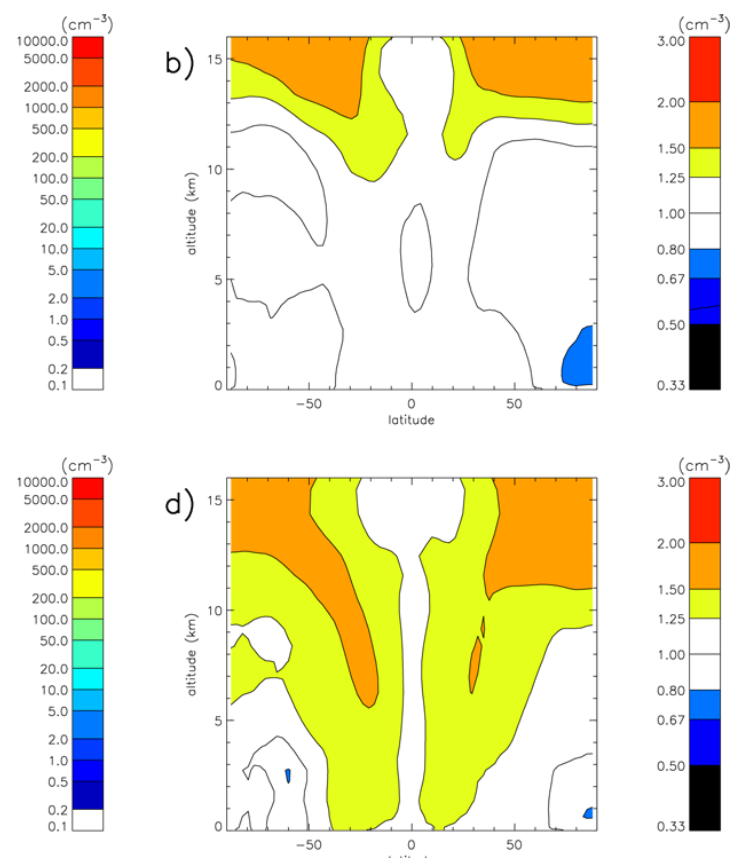

d)

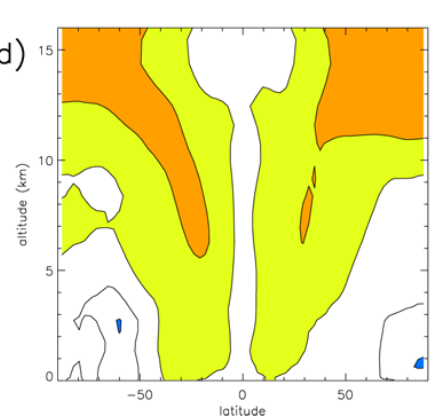

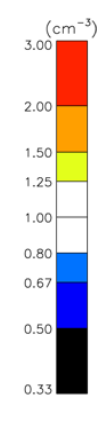

Fig. 10. Latitude-altitude plots of zonal-mean concentrations of (a) $\mathrm{CN}$ (all particles with dry diameter $>10 \mathrm{~nm})$ and (c) $\mathrm{CCN}_{50}($ all soluble particles with dry diameter $>50 \mathrm{~nm}$ ), as simulated by GLOMAP-mode (v6R) on the annual-mean. The ratio of GLOMAP-mode (v6R) to GLOMAP-bin simulated $\mathrm{CN}$ and $\mathrm{CCN}_{50}$ are shown in panels $(\mathbf{b}, \mathbf{d})$, respectively. Regions coloured yellow, orange and red in the relative bias maps indicate where GLOMAP-mode is higher than bin by 25-50, 50-100 and 100-200\%, respectively, whilst light-blue, dark-blue and black indicate where bin is higher by the same proportions. Regions where the two schemes are within $25 \%$ are colored white. 
a)

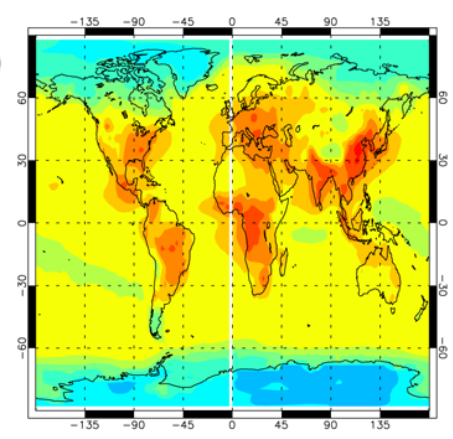

c)

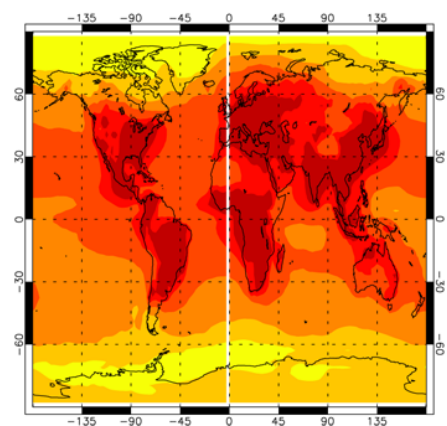

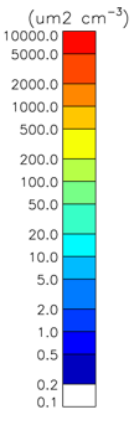

b)
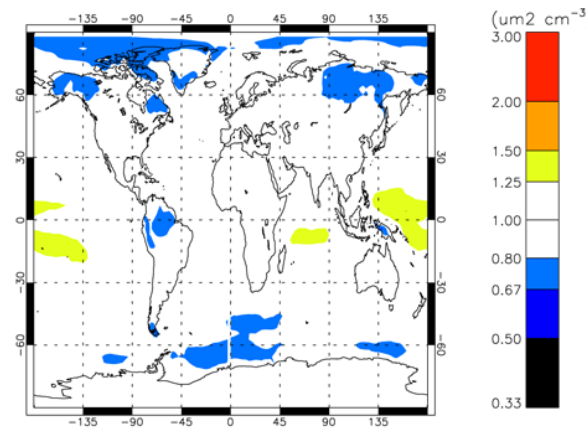

d)

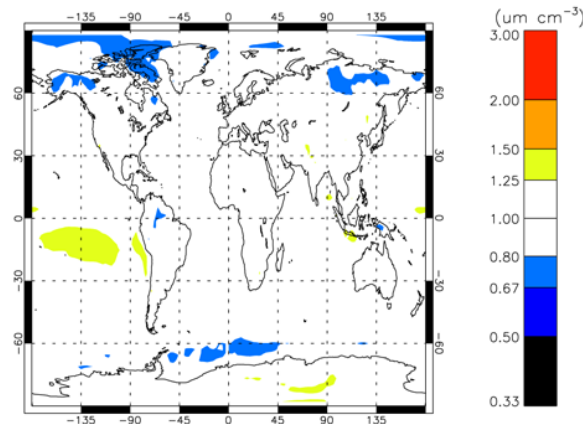

Fig. 11. Global surface maps showing (a) aerosol dry surface area density (SADdry) and (c) dry condensation sink $\left(\mathrm{CS}_{\text {dry }}\right)$ in the continuum regime as simulated by GLOMAP-mode (v6R) on the annual-mean. The ratio of GLOMAP-mode (v6R) to GLOMAP-bin simulated $\mathrm{SAD}_{\mathrm{dry}}$ and $\mathrm{CS}_{\mathrm{dry}}$ are shown in panels $(\mathbf{b}, \mathbf{d})$, respectively. Regions coloured yellow, orange and red in the relative bias maps indicate where GLOMAP-mode is higher than bin by $25-50,50-100$ and $100-200 \%$, respectively, whilst light-blue, dark-blue and black indicate where bin is higher by the same proportions. Regions where the two schemes are within $25 \%$ are colored white.

In summary, for $\mathrm{CCN}$ at the surface, the improved modal scheme is within $25 \%$ of the sectional scheme everywhere except in $30^{\circ} \mathrm{S}$ and $30^{\circ} \mathrm{N}$ marine regions. There, where photochemistry is strongest, GLOMAP-mode is high biased by up to $50 \%$, likely resulting from differences in size-resolved growth or from the simplified treatment of cloud processing. Whereas bin-mode differences in mass are larger in the free troposphere than the boundary layer, for $\mathrm{CN}$ and $\mathrm{CCN}$, relative differences in these two parts of the atmosphere are similar.

\subsection{Surface area density and condensation sink}

Figure 11 shows surface global maps of GLOMAP-mode simulated (dry) surface-area density (a) and continuumregime condensation sink (b). These two quantities represent 2 nd and 1st moment integrals across the size distribution, respectively, and are relevant as they influence rates of heterogenous chemistry and nucleation, respectively. Almost everywhere in the surface model domain, the modal scheme is within $25 \%$ of bin. The differences in surface-area density show a similar pattern as for CCN (Fig. $9 \mathrm{~b}$ and d) with a maximum in the same $30^{\circ} \mathrm{S}$ to $30^{\circ} \mathrm{N}$ marine regions, but with a high bias weaker by a factor 2 .

\subsection{All measures at different levels}

We use Taylor diagrams (Taylor et al., 2001) to summarise the bin-mode comparison for all the quantities shown in Figs. 5, 6, 8, 9, 11. Taylor diagrams combine statistical measures of the relative-variance and skewness into a single point in polar co-ordinates. In Fig. 12, the distance of each point from the origin is the ratio of the standard deviations $\left(\mathrm{sd}_{\mathrm{rat}}\right)$ between the two schemes, and the angle to the horizontal axis is the inverse cosine of the Pearson correlation coefficient $\left(\cos ^{-1}(R)\right)$. The figure illustrates $\mathrm{sd}_{\text {rat }}$ and $\cos ^{-1}(R)$ values based on the bin and mode simulated zonal-means over all latitude grid-points and on model levels between (a) $0-1 \mathrm{~km}$, (b) 1-4 km and (c) $4-8 \mathrm{~km}$ altitude.

In the lowest km (Fig. 12a), the points for all of the variables are close to the "perfect comparison" point at $y=0$ and $x=1$, illustrating the general good agreement between bin and mode seen in the figures. DMS, $\mathrm{SO}_{2}$ and sulphate compare the best, with standard deviation in GLOMAP-mode lower by only 8,5 and $3 \%$, respectively, and correlation coefficient very close to 1.0. Surface area and condensation sink are also close to the "perfect-comparison-point" with slightly higher variance in GLOMAP-mode (about $2 \%$ and $10 \%$ higher standard deviation, respectively). $\mathrm{CN}$ and $\mathrm{CCN}$ concentrations both have $20 \%$ higher standard deviation in GLOMAP-mode in the lowest km, whilst sea-salt, OC and 

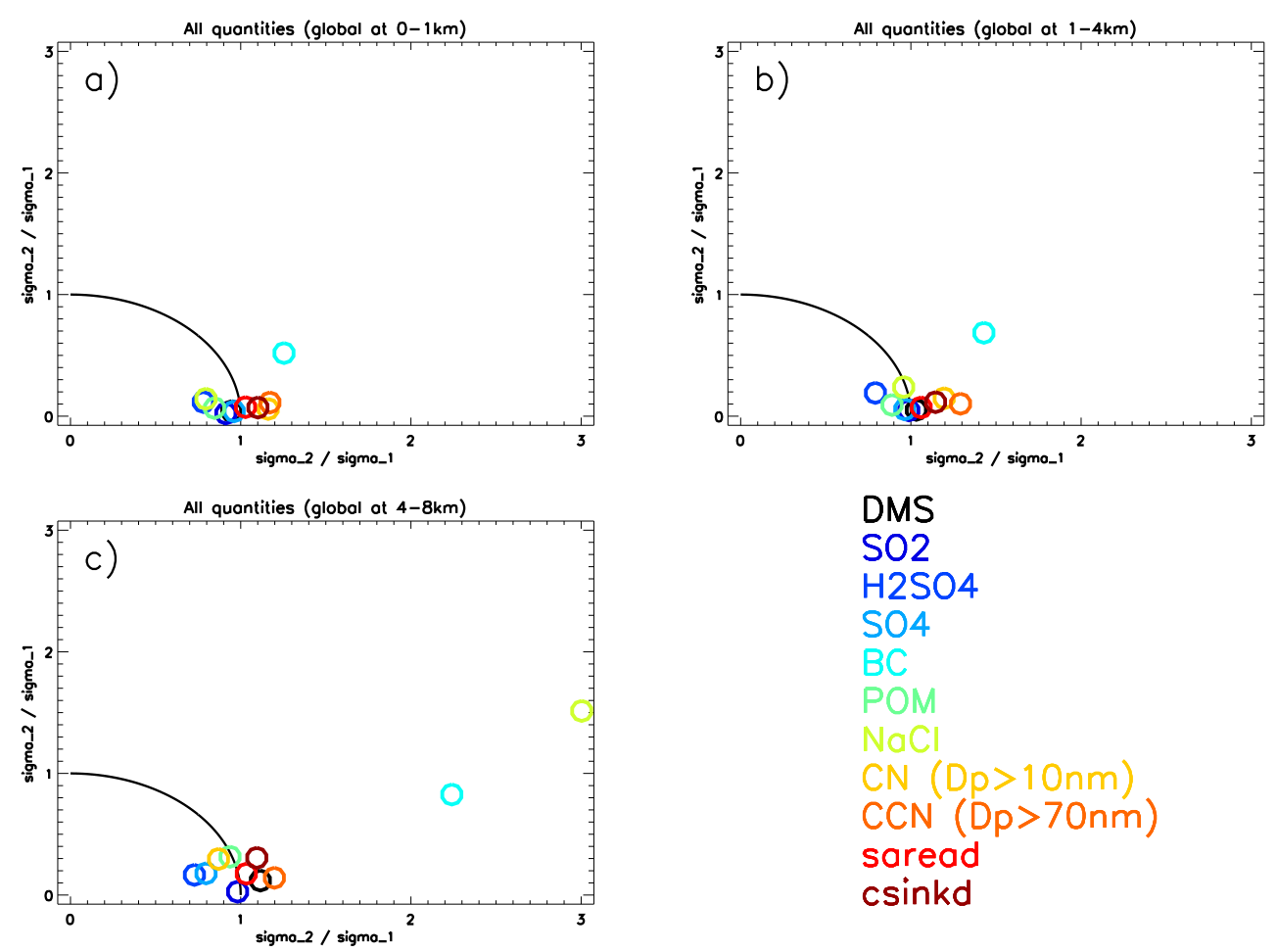

Fig. 12. Taylor diagrams showing how well GLOMAP-mode (v6R) compares against GLOMAP-bin for a range of metrics in different altitude ranges of (a) $0-1 \mathrm{~km}$, (b) $1-4 \mathrm{~km}$, (c) $4-8 \mathrm{~km}$. The distance to the perfect-model position indicating a measure of skill which combines the Pearson correlation coefficient and the relative variance for the two models runs.

$\mathrm{H}_{2} \mathrm{SO}_{4}$ have standard deviation about $20 \%, 15 \%$ and $22 \%$ lower. Simulated BC concentrations have the largest discrepancy with standard deviation $40 \%$ higher in GLOMAP-mode and only moderate correlation with GLOMAP-bin.

Between 1 and $4 \mathrm{~km}$ (Fig. 12b), there is also good agreement between the bin and mode schemes, although biases are higher than in the lowest $\mathrm{km}$, particularly for CCN and BC. In the $4-8 \mathrm{~km}$ altitude range (Fig. 12c), the differences get wider, but all points except $\mathrm{BC}$ and $\mathrm{NaCl}$ are still between the 0.7 to 1.3 range for the ratio of standard deviations, suggesting the modal scheme is performing well in the free troposphere. The bias in $\mathrm{BC}$ and $\mathrm{NaCl}$ are much larger however, with the mode-to-bin standard deviation ratio around 2.5 and 3.5 , respectively, indicative of large high biases in GLOMAP-mode in the free-troposphere compared to GLOMAP-bin (see Figs. 7 and 10d).

\section{Comparison against benchmark observational datasets}

Here we provide normalised mean bias $(b)$ and Pearson correlation coefficient $(R)$ for the GLOMAP-mode and GLOMAP-bin runs against each of the benchmark observational datasets compiled in Mann et al. (2010). The purpose of the paper is to quantify differences in predicted aerosol properties between sectional and modal aerosol mi- crophysics models, and biases with observations can sometimes be misleading due to compensating errors or missing processes. Nevertheless, by comparing to the observations, we provide some context for the differences presented in the previous sections. The GLOMAP-mode simulation here is the improved version with the narrower standard deviation, finer mode-edge radius for accumulation mode, with the run with the original settings also shown in Tables 4 and 5 to illustrate the sensitivity.

\subsection{Aerosol precursor gases}

Table 3 evaluates simulated DMS and $\mathrm{SO}_{2}$ in the bin and mode runs against observations through the annual cycle at three remote Southern Hemisphere sites (Amsterdam Island, Cape Grim and Dumont D'Urville) and against winter and summer $\mathrm{SO}_{2}$ observations across monitoring sites in Europe (EMEP, Loevblad et al., 2004) and North America (CASTNET, Holland et al., 1999). Bin-mode differences are here due to the different CTM version used, but we include them for completeness and to provide context for the biases against aerosol observations in the next sub-section.

For DMS, the models have good agreement with the observed temporal variability over the annual cycle at the three sites $(R=0.62-0.72)$, although a low bias is seen at Amsterdam Island and Dumont D'Urville. The annual variation of $\mathrm{SO}_{2}$ at the remote sites is also well captured by the 
Table 3. Simulated gas phase DMS and $\mathrm{SO}_{2}$ against surface observations for bin and mode, respectively (comma-separated). Normalised mean bias $(b)$ and Pearson correlation coefficient $(R)$ are shown for each dataset. References for the observations are 1: Nguyen et al. (1992), 2: Ayers et al. (1991), 3: Jourdain and Legrand (2001) 4: Loevblad et al. (2004) 5: Holland et al. (1999).

\begin{tabular}{llccc}
\hline Species & Site name & $b$ & $R$ & Ref. \\
\hline DMS (ann. cycle) & Amsterdam I. & $-0.42,-0.43$ & $0.71,0.72$ & 1 \\
DMS (ann. cycle) & Cape Grim & $0.19,0.17$ & $0.65,0.65$ & 2 \\
DMS (ann. cycle) & D. D'Urville & $-0.38,-0.43$ & $0.64,0.62$ & 3 \\
$\mathrm{SO}_{2}$ (ann. cycle) & Amsterdam I. & $-0.45,-0.49$ & $0.62,0.64$ & 1 \\
$\mathrm{SO}_{2}$ (ann. cycle) & Cape Grim & $4.26,3.82$ & $0.45,0.47$ & 2 \\
$\mathrm{SO}_{2}$ (Dec) & EMEP & $1.34,1.12$ & $0.66,0.61$ & 4 \\
$\mathrm{SO}_{2}$ (Jun) & EMEP & $1.32,0.84$ & $0.59,0.57$ & 4 \\
$\mathrm{SO}_{2}$ (Dec) & CASTNET & $-0.42,-0.46$ & $0.89,0.88$ & 5 \\
$\mathrm{SO}_{2}$ (Jun) & CASTNET & $0.20,-0.05$ & $0.80,0.79$ & 5 \\
\hline
\end{tabular}

Table 4. Simulated aerosol mass of sulphate, sea-salt, BC and OC against surface observations for bin and mode, respectively (commaseparated). for each of the benchmark observational datasets, Normalised mean bias $(b)$ and Pearson correlation coefficient $(R)$ are shown. The GLOMAP-mode run with the original accumulation mode standard-deviation and mode-edge radius is shown in parentheses. References for the observations are 6: Loevblad et al. (2004) 7: Malm et al. (2002) 8: from Stier et al. (2005).

\begin{tabular}{llccc}
\hline Component & Sites & $b$ & $R$ & Ref. \\
\hline $\mathrm{SO}_{4}$ (Dec) & EMEP & $-0.66,-0.70(-0.71)$ & $0.60,0.63(0.62)$ & 6 \\
$\mathrm{SO}_{4}$ (Jun) & EMEP & $0.59,0.47(0.49)$ & $0.60,0.60(0.60)$ & 6 \\
$\mathrm{SO}_{4}$ (Dec) & IMPROVE & $-0.46,-0.50(-0.50)$ & $0.76,0.72(0.72)$ & 7 \\
$\mathrm{SO}_{4}$ (Jun) & IMPROVE & $0.33,0.29(0.30)$ & $0.93,0.94(0.94)$ & 7 \\
$\mathrm{SO}_{4}$ (annual) & Univ. Miami & $0.10,0.08(0.09)$ & $0.98,0.98(0.98)$ & 8 \\
$\mathrm{NaCl}$ (annual) & Univ. Miami & $-0.41,-0.45(-0.54)$ & $0.02,0.13(0.13)$ & 8 \\
$\mathrm{BC}$ (Dec) & IMPROVE & $-0.46,-0.52(-0.52)$ & $0.44,0.41(0.41)$ & 7 \\
$\mathrm{BC}$ (Jun) & IMPROVE & $-0.44,-0.51(-0.51)$ & $0.69,0.69(0.69)$ & 7 \\
$\mathrm{OC}$ (Dec) & IMPROVE & $-0.79,-0.81(-0.81)$ & $0.46,0.43(0.43)$ & 7 \\
$\mathrm{OC}$ (Jun) & IMPROVE & $-0.36,-0.46(-0.45)$ & $0.84,0.84(0.84)$ & 7 \\
\hline
\end{tabular}

models $(R=0.45-0.6)$. While the magnitude of $\mathrm{SO}_{2}$ compares within a factor of 2 on average at Amsterdam Island $(b=(-0.45)-(-0.49))$, there is a strong high bias $(b=3.82-$ 4.26) at Cape Grim, likely due to the observations (Ayers et al., 1991) representing only clean air-masses and the coarse horizontal grid in the model run.

The spatial variability in simulated continental $\mathrm{SO}_{2}$ compares well to the observations in both Europe $(R=0.57-$ $0.62)$ and North America $(R=0.79-0.89)$. However, there is a high bias in $\mathrm{SO}_{2}$ in Europe in summer $(b=0.84-1.32)$ and winter $(b=1.12-1.34)$, whereas in North America, the magnitude compares better in summer $(b=-0.05-0.20)$ than in winter $(b=-0.42--0.46)$. The high bias in modeled $\mathrm{SO}_{2}$ over Europe is consistent with other large scale models and may be due to uncertainties in vertical mixing, emission heights (de Meij et al., 2006) or wet scavenging (Rasch et al., 2000).

\subsection{Speciated particle masses}

In Table 4 we present $b$ and $R$ values for the bin and mode runs, evaluating simulated surface aerosol mass of sulphate, sea-salt, BC and OC. For Europe and North America, we compare winter and summer model values against year-2000 filter measurements in Europe (EMEP, Loevblad et al., 2004) and North America (IMPROVE, Malm et al., 2002). We also evaluate marine simulated sulphate and sea-salt by comparing to annual-mean observations over several years from monitoring stations in the University of Miami network (values from Stier et al., 2005).

In the previous section, we saw that simulated surface sulphate in the bin and mode schemes compares within $25 \%$ everywhere except in the Arctic and free-troposphere. Here, we examine how close they compare to the observations. The bin and mode runs represent well the observed spatial variability in Europe (each have $R=0.63$ in winter and 0.60 in summer) and particularly well in North America (bin, mode $R=0.76,0.72$ in winter and $0.93,0.94$ in summer). However, in both schemes, sulphate has a winter low bias in both 
Table 5. Simulated CN, CCN and size-resolved number concentrations for bin and mode, respectively (comma-separated) against each of the benchmark observational datasets. Normalised mean bias $(b)$ and Pearson correlation coefficient $(R)$ are shown. The GLOMAP-mode run with the original accumulation mode standard-deviation and mode-edge radius is shown in parentheses. References for the observations are 9: Heintzenberg et al. (2000), 10: Clarke and Kapustin et al. (2002), 11: from Lauer et al. (2005), 12: World Data Centre for Aerosols webpage (http://wdca.jrc.it), 13: from Spracklen et al., 2011.

\begin{tabular}{|c|c|c|c|c|c|}
\hline Property & Size-range & Location & $b$ & $R$ & Ref. \\
\hline Surf CN (ann. mean) & $D_{\mathrm{p}}>10 \mathrm{~nm}$ & Global marine & $-0.19,-0.14(-0.13)$ & $0.12,0.12(0.12)$ & 9 \\
\hline Surf $\mathrm{N}_{\text {Ait }}($ ann. mean) & $100>D_{\mathrm{p}}>10 \mathrm{~nm}$ & Global marine & $-0.33,-0.41(-0.31)$ & $-0.23,-0.26(-0.28)$ & 9 \\
\hline Surf $\mathrm{N}_{\mathrm{acc}}$ (ann. mean) & $1000>D_{\mathrm{p}}>100 \mathrm{~nm}$ & Global marine & $0.05,0.16(0.03)$ & $0.73,0.77(0.77)$ & 9 \\
\hline Prof CN (ann. mean) & $D_{\mathrm{p}}>3 \mathrm{~nm}$ & N.H. marine & $-0.31,-0.08(-0.08)$ & $0.84,0.85(0.85)$ & 10 \\
\hline Prof CN (ann. mean) & $D_{\mathrm{p}}>3 \mathrm{~nm}$ & Trop'l marine & $-0.66,-0.54(-0.54)$ & $0.73,0.70(0.70)$ & 10 \\
\hline Prof CN (ann. mean) & $D_{\mathrm{p}}>3 \mathrm{~nm}$ & S.H. marine & $-0.42,-0.07(-0.07)$ & $0.84,0.87(0.87)$ & 10 \\
\hline Prof $\mathrm{N}_{5}$ (ann. mean) & $D_{\mathrm{p}}>5 \mathrm{~nm}$ & Germany & $-0.54,-0.42(-0.41)$ & $0.95,0.90(0.91)$ & 11 \\
\hline Prof $\mathrm{N}_{15}$ (ann. mean) & $D_{\mathrm{p}}>15 \mathrm{~nm}$ & Germany & $-0.36,-0.31(-0.29)$ & $0.95,0.93(0.93)$ & 11 \\
\hline Prof $\mathrm{N}_{120}$ (ann. mean) & $D_{\mathrm{p}}>120 \mathrm{~nm}$ & Germany & $-0.19,0.26(0.00)$ & $0.99,0.99(0.99)$ & 11 \\
\hline Surf CN (ann. cycle) & $D_{\mathrm{p}}>10 \mathrm{~nm}$ & Jungfrau’ (FT) & $-0.40,-0.40(-0.37)$ & $0.14,0.23(0.30)$ & 12 \\
\hline Surf CN (ann. cycle) & $D_{\mathrm{p}}>14 \mathrm{~nm}$ & Mauna Loa $(\mathrm{FT})$ & $-0.16,-0.19(-0.17)$ & $-0.25,-0.33(-0.35)$ & 12 \\
\hline Surf CN (ann. cycle) & $D_{\mathrm{p}}>14 \mathrm{~nm}$ & South Pole (FT) & $0.12,-0.28(-0.29)$ & $0.76,0.77(0.77)$ & 12 \\
\hline Surf CN (ann. cycle) & $D_{\mathrm{p}}>10 \mathrm{~nm}$ & Mace H'd (MBL) & $-0.55,-0.53(-0.53)$ & $0.18,0.17(0.19)$ & 12 \\
\hline Surf CN (ann. cycle) & $D_{\mathrm{p}}>14 \mathrm{~nm}$ & Neum'r (MBL) & $-0.67,-0.76(-0.75)$ & $0.77,0.74(0.74)$ & 12 \\
\hline Surf CN (ann. cycle) & $D_{\mathrm{p}}>14 \mathrm{~nm}$ & Barrow (MBL) & $-0.81,-0.84(-0.84)$ & $-0.37,-0.24(-0.18)$ & 12 \\
\hline Surf CN (ann. cycle) & $D_{\mathrm{p}}>14 \mathrm{~nm}$ & Samoa (MBL) & $-0.44,-0.47(-0.48)$ & $-0.42,-0.43(-0.41)$ & 12 \\
\hline Surf CN (ann. cycle) & $D_{\mathrm{p}}>14 \mathrm{~nm}$ & Trin'd H'd (MBL) & $-0.04,-0.02(-0.01)$ & $0.28,0.37(0.35)$ & 12 \\
\hline Surf CN (ann. cycle) & $D_{\mathrm{p}}>3 \mathrm{~nm}$ & Cape Grim (MBL) & $-0.64,-0.61(-0.61)$ & $0.34,0.43(0.43)$ & 12 \\
\hline Surf CN (ann. cycle) & $D_{\mathrm{p}}>10 \mathrm{~nm}$ & SG Plains (CBL) & $-0.48,-0.43(-0.43)$ & $0.38,0.47(0.46)$ & 12 \\
\hline Surf CN (ann. cycle) & $D_{\mathrm{p}}>14 \mathrm{~nm}$ & Bondville (CBL) & $-0.44,-0.36(-0.35)$ & $0.08,0.00(0.00)$ & 12 \\
\hline Surf CN (ann. cycle) & $D_{\mathrm{p}}>10 \mathrm{~nm}$ & Pallas (CBL) & $-0.39,-0.41(-0.39)$ & $-0.51,-0.60(-0.54)$ & 12 \\
\hline Surf CN (ann. cycle) & $D_{\mathrm{p}}>3 \mathrm{~nm}$ & Hoh’berg (CBL) & $-0.14,-0.06(-0.04)$ & $0.47,-0.02(0.02)$ & 12 \\
\hline Surf CCN (monthly) & & Global & $0.12,0.12(0.12)$ & $0.72,0.67(0.68)$ & 13 \\
\hline Surf CCN (monthly) & & Global (marine) & $0.66,0.74(0.75)$ & $0.27,0.34(0.34)$ & 13 \\
\hline Surf CCN0.5 (ann. cycle) & & Mace Head & $0.49,0.43(0.43)$ & $0.34,0.38(0.38)$ & 13 \\
\hline Surf CCN0.23 (ann. cycle) & & Cape Grim & $1.03,1.47(1.47)$ & $0.45,0.47(0.47)$ & 13 \\
\hline Surf CCN1.2 (ann. cycle) & & Cape Grim & $0.61,0.62(0.62)$ & $0.68,0.59(0.59)$ & 13 \\
\hline
\end{tabular}

regions (bin, mode $b=-0.66,-0.70$ for Europe and -0.46 , -0.50 in North America) and a summer high bias $(b=0.59$, 0.47 for Europe and 0.33, 0.29 for North America). Comparing annual-mean sulphate at the University of Miami remote marine sites, both schemes are similar, representing the observed spatial variability very well $(R=0.98)$ with only a very weak bias ( $b=0.10,0.08$ for bin, mode). The European sulphate winter low bias is likely mainly caused by the $\mathrm{SO}_{2}$ low bias seen in Sect. 6.1, although the omission of in-cloud sulphate production via ozone may also be a factor. Other sulphate production mechanisms not included here could also be important, including via heterogeneous chemistry on the surface of dust particles (e.g., Bauer and Koch, 2005) or other reactions with transition metals (Alexander et al., 2009).

Sea-salt in GLOMAP-bin is slightly longer lived than in GLOMAP-mode (see Table 2) leading to a slightly higher burden. At the surface (Fig. 5), GLOMAP-mode sea-salt was slightly lower over the Southern Ocean and higher in the tropics, where wet deposition dominates removal processes. Against the annual-mean observations, simulated sea-salt in both versions is only weakly spatially correlated against the University of Miami sites ( $R=0.13$ for mode, 0.02 for bin) and the magnitude is rather low biased $(b=-0.41,-0.45$ in bin, mode). Note that this low bias in GLOMAP-mode seasalt is considerably worse $(-0.54)$ in the original run with the coarser accumulation-coarse mode edge-radius underlining the benefit gained from the revision to the modal settings.

Both schemes have quite good correlation with $\mathrm{BC}$ at the North American sites with $R=0.44,0.41$ for bin and mode in winter and $R=0.69$ for both in summer. However, there is a low bias in both winter (bin, mode $b=-0.46,-0.52$ ) and summer $(-0.44,-0.51)$ with mode slightly more low biased in each case. Against the observations of organic 
carbon, both schemes have a very strong low bias during winter ( $b=-0.79,-0.81$ for bin, mode) and moderate low bias during summer $(b=-0.36,-0.46$ for bin, mode). The correlation scores are almost identical for bin and mode and it is notable that $R$ for both schemes is higher for OC than $\mathrm{BC}$ during summer but similar during winter. There is also a worse winter low bias in $\mathrm{OC}$ than $\mathrm{BC}$ for both schemes which suggests that simulation of winter organic aerosol is poorly simulated here.

\subsection{Size-resolved particle number concentrations}

Table 5 shows $b$ and $R$ values for simulated size-resolved particle number concentrations against the datasets compiled in Mann et al. (2010). The climatology of aerosol properties from $30 \mathrm{yr}$ of marine particle size distribution measurements (mainly from cruises in field campaigns) compiled by Heintzenberg et al. (2000) is used to constrain simulated total, Aitken and accumulation mode number concentrations in the marine boundary layer. The vertical profile of total particle concentrations in marine regions is tested based on the Pacific aircraft observations compiled in Clarke and Kapustin (2002). Continental profiles of size-resolved number concentrations are evaluated against aircraft observations over Germany from the LACE campaign (Petzold et al., 2002) based on the $1 \mathrm{~km}$-resolution profiles compiled by Lauer et al. (2005). Several years of condensation particle counter measurements at Global Atmospheric Watch (GAW) stations covering free troposphere (FT), marine boundary layer (MBL) and continental boundary layer (CBL) environments (see Mann et al., 2010 for the range of years covered) is used as the observational benchmark for simulated total particle concentrations across the annual cycle. Finally, the CCN database compiled by Spracklen et al. (2011) is used to assess simulated $\mathrm{CCN}$ concentrations covering a range of supersaturations and environments.

We first describe the methods used to derive model values to compare against these datasets. For comparison to the Aitken and accumulation mode number concentrations (dataset 9), model values are zonal means (for gridboxes over ocean) of particle concentrations in the dry-diameter range $10-100$ and $100-1000 \mathrm{~nm}$, respectively. When comparing to dataset 11 (CN observations at the GAW sites, details in Mann et al., 2010), model values are concentrations of particles larger than the instrument cut-off dry-diameter $(3 \mathrm{~nm}$ for Cape Grim and Hohenpeissenberg, $10 \mathrm{~nm}$ for Jungfraujoch, Mace Head, Southern Great Plains and Pallas, and $14 \mathrm{~nm}$ for the other seven sites). For the $\mathrm{CN}$ comparisons in datasets 9 , 10 and 12, and the size-resolved concentrations in datasets 9 and 11, both soluble and insoluble modes/distributions are included. In comparing with dataset 13 (the CCN compilation from Spracklen et al., 2011), only particles in the soluble modes/distribution are included. The GLOMAP-bin CCN concentrations are calculated following the method used in Spracklen et al. (2011), determined by the simulated size- resolved composition in the soluble distribution. The kappaKohler approach (Petters and Kreidenweis, 2007) is used with values of $0.61,1.28,0.0$ and 0.27 for sulfate, sea-salt, $\mathrm{BC}$ and POM, respectively. The identical approach was also followed in GLOMAP-mode, with the simulated number and component mass concentrations in each mode interpolated onto a bin-resolved dry radius grid using the standard devations and number- and mass-weighted geometric mean radii for each mode. The monthly-mean CCN corresponding to the month of the observation is used. The simulated $\mathrm{CN}$ concentrations to compare at the GAW sites are from the model level corresponding closest to the altitude of the measurement site.

The variation of marine $\mathrm{CN}$ concentrations in both schemes correlates only weakly with the Heintzenberg et al. (2000) observations ( $R=0.12$ for both bin and mode) although the average bias is small $(b=-0.19$ for bin, -0.14 for mode). For particles in the Aitken mode, both schemes fail to correlate with the observations $(R=-0.23,-0.26$ for bin, mode), with the bin scheme having smaller low-bias ( $b=-0.33$ compared to -0.41 for mode). The negative correlation reflects substantial underestimation in the Southern Hemisphere and overestimation in the Northern Hemisphere (see Fig. 13a), and although the difference between bin and mode may be significant, neither correlates with the measurements. However, simulated accumulation mode number concentrations (Fig. 13b) correlate very well with the observations in both schemes ( $R=0.73$ for bin, 0.77 for mode) and also both have low bias ( $b=0.05$ for bin, 0.16 for mode). Note that although the revision to the modal settings does not greatly improve the GLOMAP-mode simulated number concentration in the accumulation mode, Fig. 3 clearly showed much better agreement in simulated size against the observations with the revised settings.

The bin and modal schemes show good agreement to the aircraft profile observed concentrations of ultrafine condensation nuclei (UCN, $D_{\mathrm{p}}>3 \mathrm{~nm}$ ) over the Pacific from Clarke and Kapustin (2002), see Fig. 14. In all three latitude ranges GLOMAP-mode is less low-biased $(b=-0.08$, -0.54 and -0.07$)$ and better correlated $(R=0.85,0.70$ and $0.87)$ than GLOMAP-bin $(b=-0.31,-0.66$ and -0.42 ; $R=0.84,0.73$ and 0.84 ) against the observations.

Figure 15 shows a comparison to aircraft profiles over Germany of particle concentrations larger than 5,15 and $120 \mathrm{~nm}$ dry-diameter $\left(\mathrm{N}_{5}, \mathrm{~N}_{15}\right.$ and $\left.\mathrm{N}_{120}\right)$. The bin and mode schemes follow each other very closely, with $\mathrm{N}_{5}$ in both moderately low-biased (bin and mode $b=-0.54$ and -0.42 ) albeit with good correlation ( $R=0.95$ and 0.90 for bin ande mode). Similarly, excellent agreement between the two schemes is seen for $\mathrm{N}_{15}$, with a more moderate low bias $(b=-0.36$ and -0.31 ). Comparing to the observed $\mathrm{N}_{120}$ profiles, both schemes have excellent correlation with the observations ( $R=0.99)$ with bin and mode slightly high-biased $(b=0.19$ and 0.26 for bin and mode).

At the free troposphere GAW sites, the bin and mode schemes are in very close agreement, and compare generally 
well against the observations. At Mauna Loa and Jungfraujoch, the bin and mode schemes have only a weak to moderate low bias in all months, $(b=-0.16,-0.19$ and -0.40 , -0.40 , respectively). At South Pole the seasonal cycle is also well captured $(R=0.76,0.77)$, although the winter minimum in bin and mode are a factor 3 and 4 too low compared to the observations (not shown). At marine GAW sites, bin and mode again have similar skill against the observations, both generally underpredicting either moderately ( $b=-0.44$ to -0.47 at Samoa) or more substantially at the coastal mid-latitude $(b=-0.64,-0.61$ at Cape Grim and $-0.55,-0.53$ at Mace Head) and high-latitude sites ( $b=-0.67,-0.76$ at Neumayer and $-0.81,-0.84$ at Barrow). At the continental GAW sites, the two schemes have a similar level of agreement with the observations, with weak to moderate low biases and poor correlation over the seasonal cycle. This poor correlation is consistent with Spracklen et al. (2010) who found that simulations with binary nucleation and primary emissions (the processes included here) could not explain the continental seasonal $\mathrm{CN}$ cycle, whereas considerably improved correlation was found when boundary layer nucleation was included.

Against the Spracklen et al. (2011) compilation of CCN measurements, both schemes compare very well with only a very weak high bias ( $b=0.12$ for both) and good spatial correlation ( $R=0.72$ for bin, 0.67 for mode), see Fig. 16 . When only $\mathrm{CCN}$ measurements at marine boundary layer sites are included, the bias is larger $(0.66,0.74$ for bin, mode $)$ with only weak correlation $(0.27,0.34$ for bin, mode). In Fig. 17, we compare the bin and mode CCN annual cycle to observations at Mace Head (Reade et al., 2006) and Cape Grim (Ayers and Gras, 1991). A high CCN bias is clearly evident at Cape Grim, and is slightly worse in GLOMAPmode $(b=0.62,1.47$ for $S=1.2,0.23 \%)$ than GLOMAPbin $(b=0.61,1.03)$ and both schemes are also high-biased at Mace Head ( $b=0.49$ for bin, 0.43 for mode). Note that one might expect the model CCN to be higher than observed at Cape Grim since it covers all wind directions, whereas the measurements are for marine air masses only.

\section{Discussion on sub-micron mode widths}

In Sect. 3, we found that size distributions simulated by the sectional scheme, which can evolve freely in response to the processes (without parametric constraints) result in a largeend tail of the accumulation mode consistent with $\sigma=1.4$. The original GLOMAP-mode settings for the standard deviation were taken from the literature, matching those in the M7/HAM models (Vignati et al., 2004; Stier et al., 2005) with $\sigma=1.59$ for all three sub- $\mu$ m modes. The value of 1.59 originates from Wilson et al. (2001), and represents a compromise between values suggested by self-preserving theory (1.45) and from observations (1.4-2.0). In the light of the
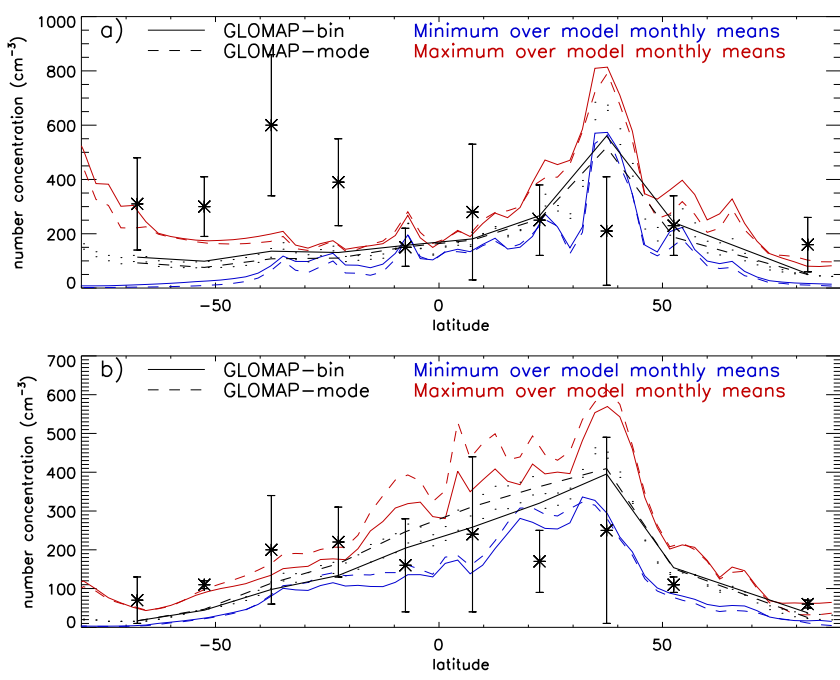

Fig. 13. Simulated marine surface zonal-mean size-resolved number concentration in (a) Aitken mode and (b) accumulation mode, compared to those in the observed climatology (asterisks) for the marine boundary layer (Heintzenberg et al., 2000). The black lines show simulated annual mean values (averaged to the 15-degree grid) and the blue/red lines show minimum/maximum monthlymean values. In (a) and (b) the solid lines are for GLOMAP-bin with the dashed lines for GLOMAP-mode (v6R). The error-bars around the asterisks show the observed standard-deviation in each latitude band. Values of $b$ and $R$ are shown in Table 5 from model annual-means (ocean grid boxes only) and by averaging up to the 15 degree grid to match the observations.

findings in Sect. 3, we revisit this issue and review values from observations in the literature.

Whitby (1978) presented a synthesis of observed size distributions from a range of environments, which suggested $\sigma$ in sub-micron modes is generally between 1.6 and 2.2, although lower values were observed in marine regions. Heintzenberg et al. (2000) compiled $30 \mathrm{yr}$ of marine dry size distribution observations and presented a global variation of Aitken and accumulation mode lognormal fit parameters on a 15 degree latitude grid. Their reported observed values of the accumulation mode standard deviation $\sigma_{\text {acc }}$ are between 1.4 and 1.6 with most values at 1.4. Birmili et al. (2001) follow a similar approach from lognormal fits to size distribution measurements at a continental site in Germany. They find the Aitken mode is generally wider than the accumulation mode with $\sigma_{\text {Ait }}$ tending to vary between 1.55 and 1.73 , and $\sigma_{\text {acc }}$ between 1.41 and 1.57. However, Pirjola et al. (1999) find the opposite from measurements at the Hyytiala boreal forest site in Finland (Makela et al., 1997), finding $\sigma_{\text {Ait }}=1.5$ and $\sigma_{\text {acc }}=1$.7. Petzold et al. (2002) applied tri-modal lognormal fits to size distributions measured over Germany by aircraftborne optical particle counters and found $\sigma$ for the accumulation mode to vary between 1.28 and 1.6 with the majority of values between 1.3 and 1.4. Asmi et al. (2011) present a synthesis of sub- $\mu \mathrm{m}$ size distribution measurements from 

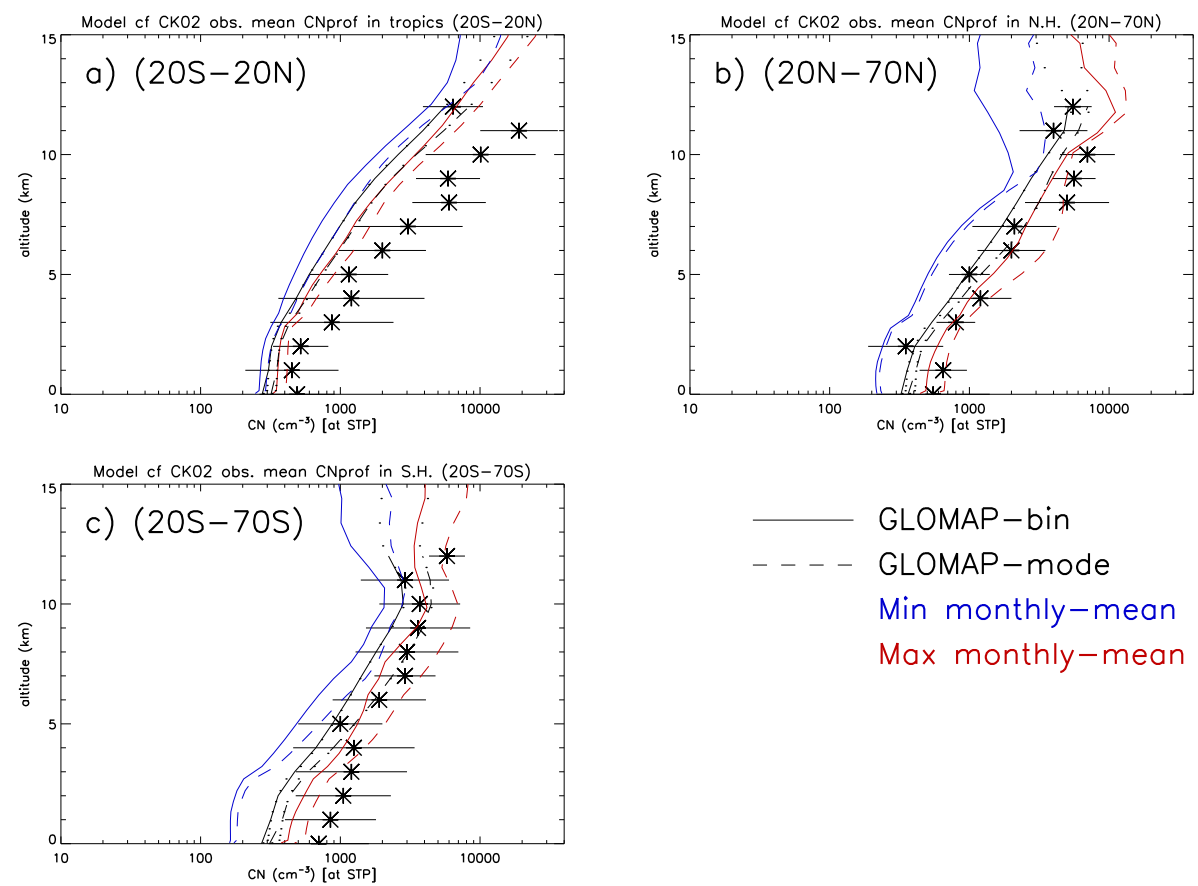

Fig. 14. Simulated ultrafine $\mathrm{CN}\left(D_{\mathrm{p}}>3 \mathrm{~nm}\right.$ ) profiles (lines) over the Pacific and Southern Oceans compared to aircraft observations (asterisks) from Clarke and Kapustin (2002) in the latitude ranges (a) $20^{\circ} \mathrm{S}-20^{\circ} \mathrm{N}$, (b) $20^{\circ} \mathrm{N}-70^{\circ} \mathrm{N}$ and (c) $20^{\circ} \mathrm{S}-70^{\circ} \mathrm{S}$. Model CN concentrations are at standard temperature and pressure and means over the longitude ranges (a) $135-180^{\circ} \mathrm{E}$, (b) $175-270^{\circ} \mathrm{E}$ and (c) $200-240^{\circ} \mathrm{E}$ respectively, following the approach in Spracklen et al. (2005). Values of $b$ and $R$ are calculated for each region (see Table 5) from model values interpolated to a $1 \mathrm{~km}$ grid to match the observations. The error-bars around the asterisks show the observed standard-deviation in each $1 \mathrm{~km}$ altitude range. The black line shows simulated annual mean profile and the blue/red lines show minimum/maximum monthly-mean values for GLOMAP-bin (solid) and GLOMAP-mode v6R (dashed).

24 sites in Europe and applied bi-modal lognormal fits to the median size distributions in the $20-500 \mathrm{~nm}$ dry-diameter range. They find large spatial variation in $\sigma$, with values for the Aitken and accumulation modes being in the range 1.472.49 and $1.27-2.44$, respectively.

Overall, although the observations suggest $\sigma$ varies substantially between different sites and environments, our revised values of 1.59 and 1.40 for the constant standard deviations for Aitken and accumulation soluble modes are reasonably consistent with findings from size distributions measured in both marine and continental regions. We also note that Pirjola et al. (1999) found that the self-preserving distribution for modal schemes which allow $\sigma$ to evolve in the model gave values in the range 1.36-1.45, giving additional evidence in support of reducing $\sigma$ for the accumulation mode (the longest lived of the modes) from 1.59 to 1.40.

\section{Conclusions}

In this study we have, for the first time in a 3-D global model, carried out a thorough intercomparison of integral particle properties simulated by two-moment sectional and modal aerosol dynamics schemes. The assessment was carried out using the same offline chemistry transport model with equiv- alent meteorological, oxidant and cloud fields to help isolate simulated differences to the sophistication of the aerosol scheme.

We have compared size distributions simulated by the two schemes to constrain the choice of parameters in the modal scheme, and have quantified biases in size-resolved particle concentrations. We find that a value of 1.59 for the accumulation mode standard deviation $\left(\sigma_{\mathrm{acc}}\right)$ is too wide, and reducing this and the separation-dry-radius between the accumulation and coarse modes $\left(r_{3,4}\right)$, we achieve much better agreement against the bin scheme. With $\sigma_{\text {acc }}$ set to 1.59 , the particles in the large-end tail of the accumulation mode were overestimated, whereas a value of 1.40 fits much better the size distribution in the sectional scheme and, in general, against observations. With $r_{3,4}$ at $500 \mathrm{~nm}$, coarse particle concentrations were biased low with the bin scheme, but reducing $r_{3,4}$ to $250 \mathrm{~nm}$ led to excellent agreement, avoiding problems in the previous configuration whereby the lower-end of the coarse mode size-resolved sea-spray emissions flux was emitting in the model accumulation-soluble mode.

We have shown that these revisions of the size-settings in the modal scheme lead to improved agreement against the sectional scheme in terms of simulated sea-salt, $\mathrm{CN}$, $\mathrm{CCN}_{50}$ and $\mathrm{N}_{150}$. Whereas the original configuration of 

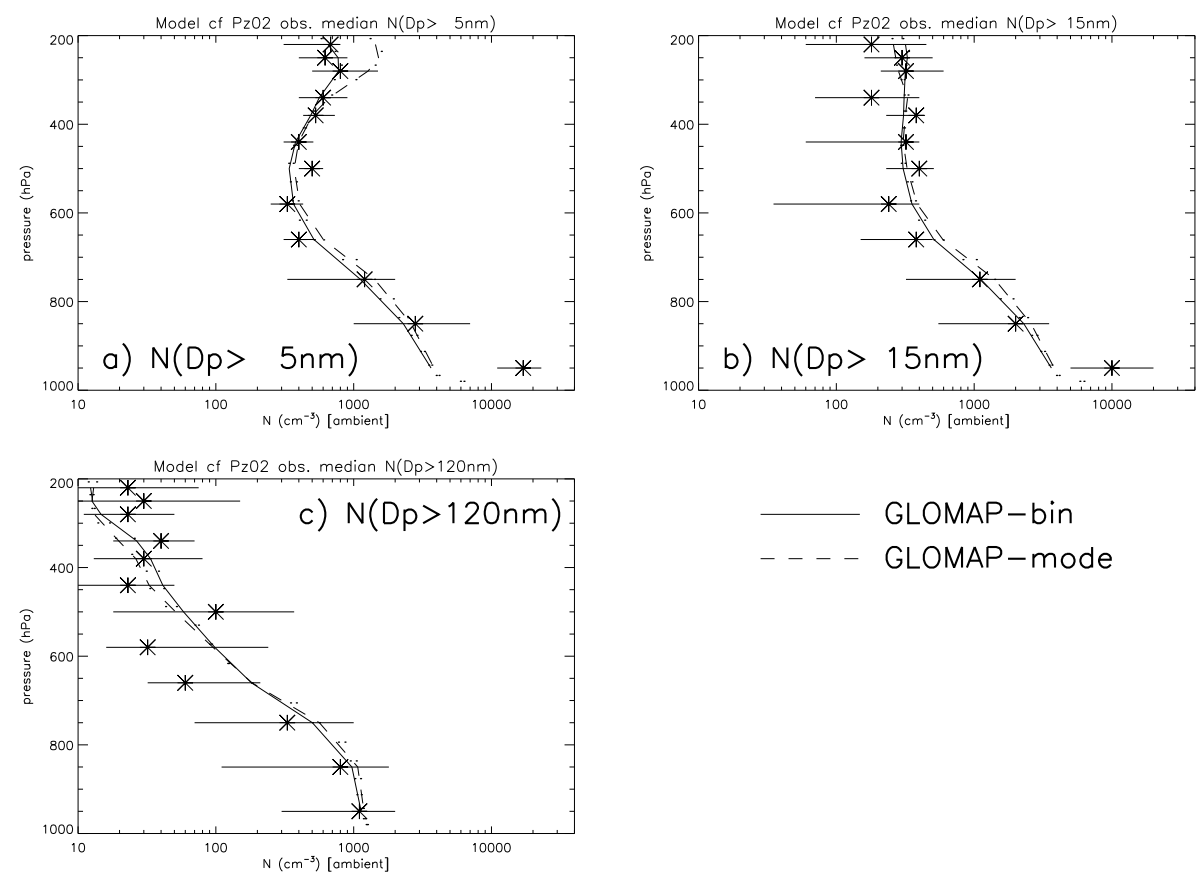

Fig. 15. Simulated vertical profiles of size-resolved number concentration compared to aircraft observations (Petzold et al., 2002) over NE Germany $\left(13.5-14.5^{\circ} \mathrm{E}, 51.5-52.7^{\circ} \mathrm{N}\right)$ for particles larger than (a) $5 \mathrm{~nm}$, (b) $15 \mathrm{~nm}$ and (c) $120 \mathrm{~nm}$ dry diameter. Values of $b$ and $R$ are shown in Table 5 for each size-range from model values interpolated to a $1 \mathrm{~km}$ grid to match the observations. The error-bars around the asterisks show the observed 25th and 75th percentiles in each $1 \mathrm{~km}$ altitude range. The black lines show the August mean values for GLOMAP-bin (solid) and GLOMAP-mode v6R (dashed).
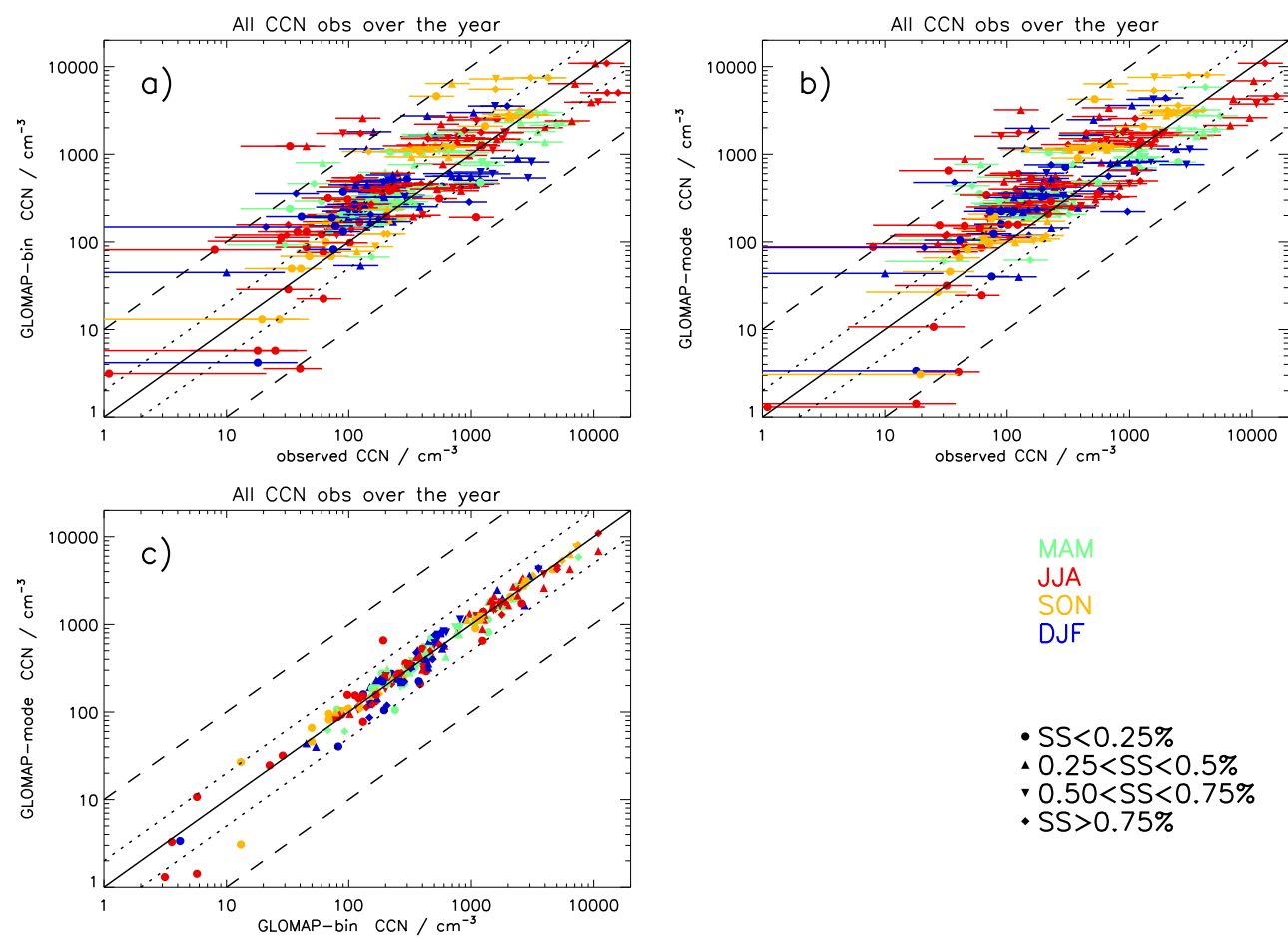

Fig. 16. Scatter plots showing comparison of simulated CCN concentrations against observations at the range of sites compiled in Spracklen et al. (2011) for (a) GLOMAP-mode (v6R), (b) GLOMAP-bin. A scatter plot of GLOMAP-bin against GLOMAP-mode simulated CCN is shown in panel (c). Each model CCN is calculated based on the stated supersaturation for the corresponding measurement, following the method in Spracklen et al. (2011), using the monthly-mean for the month the observation was made. 

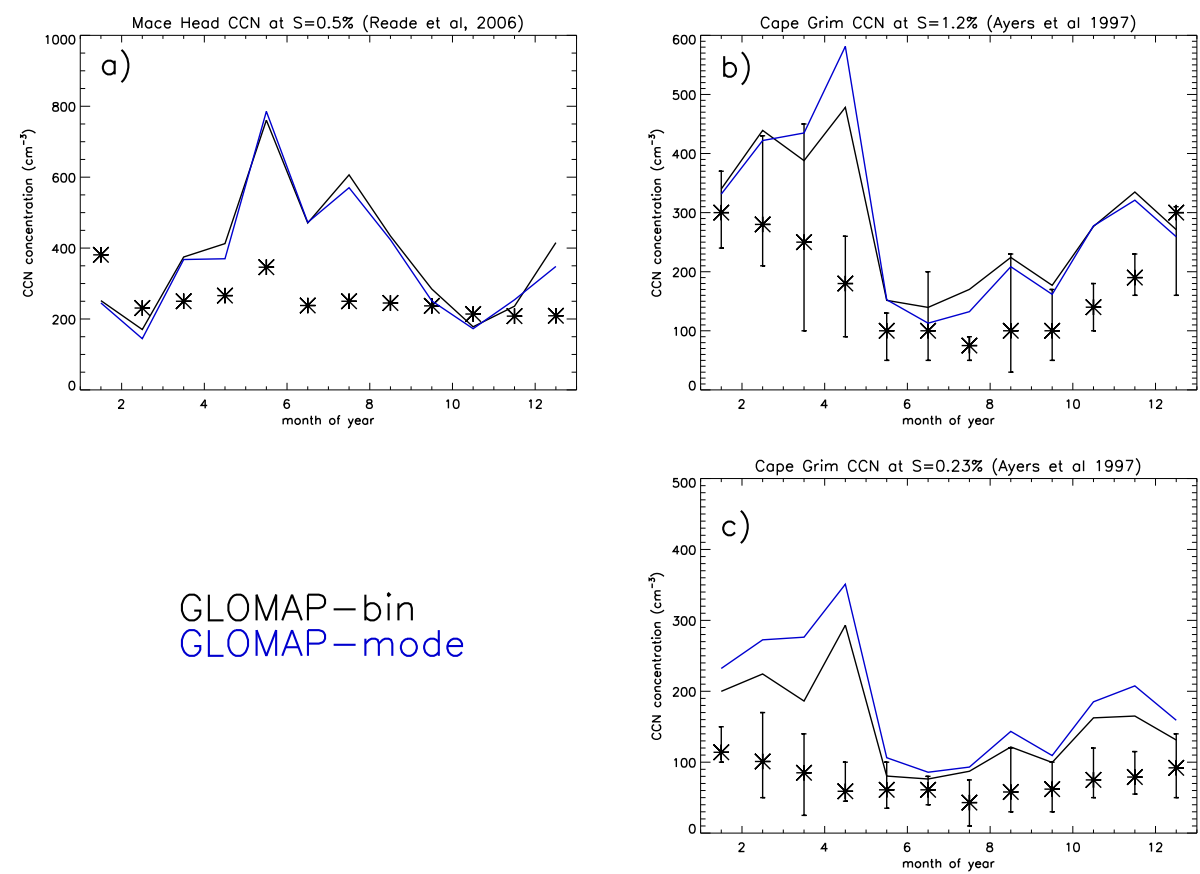

Fig. 17. The simulated annual cycle of $\mathrm{CCN}$ concentrations (solid lines) against observations (asterisks) at Mace Head and Cape Grim. The measurements at Mace Head (a) are with $0.5 \%$ superstaturation (Reade et al., 2006) whilst the comparison at Cape Grim is shown for measured CCN concentrations at supersaturations of (b) $1.2 \%$ and (c) $0.23 \%$, see Ayers and Gras (1991). Vertical bars around the Cape Grim observations show the observed range from 1981-1989. Solid line shows GLOMAP-bin, dashed line is GLOMAP-mode (v6R).

GLOMAP-mode showed low-biased $\mathrm{N}_{150}$ up to a factor two compared to GLOMAP-bin in some regions, the revised configuration approximately halved this bias in almost all regions (see Table 1).

With the improved configuration, globally and vertically integrated burdens (and hence lifetimes) of sulphate, seasalt, BC and POM in the two schemes compare well, with GLOMAP-mode within about $10 \%$ of GLOMAP-bin.

At the surface, speciated sub- $\mu \mathrm{m}$ aerosol mass (sulphate, $\mathrm{BC}$ and $\mathrm{OC}$ ) in the bin and mode schemes compared very well in general (within $25 \%$ ) in both marine and continental regions. GLOMAP-mode sulphate mass has a moderate low bias compared to GLOMAP-bin in the Arctic however, and in regions with strong biomass burning emissions moderate biases were also seen. Generally, biases were slightly larger between bin and mode for mass in the coarse mode (sea-salt), although good general agreement was still found.

In the free troposphere, bin-mode differences in simulated mass are larger than at the surface, with the modal scheme higher there, which we attribute to the coarser size resolution in the treatment of wet removal. In the sectional scheme, highly size-resolved nucleation scavenging rates are possible, whereas the modal scheme cannot differentiate between particles within one size class.

With the improved settings, the modal scheme performs well against the bin scheme with differences in simulated $\mathrm{CN}$, surface area density, and condensation sink less than
$25 \%$ in almost all regions at the surface. Differences in simulated surface $\mathrm{CCN}$ are everywhere less than $25 \%$, except in $30^{\circ} \mathrm{S}$ to $30^{\circ} \mathrm{N}$ marine regions, where the modal scheme is high biased by $\approx 50 \%$, likely caused by too effective growth and the simplified cloud processing approach.

Although there are substantial bin-mode differences in mass in the free troposphere and remote locations, differences are generally less for aerosol microphysical integral properties such as $\mathrm{CN}, \mathrm{CCN}$, surface area and condensation sink. This suggests that the simplification from bins to modes affects processes which influence the accumulation and coarse parts of the size distribution (where most of the mass resides) more than those at sub- $100 \mathrm{~nm}$ sizes (which contain most of the number). We infer from this, that although growth by coagulation or condensation is better treated by the sectional scheme, the biases arising from the simplification to the modal scheme are larger on processes such as cloud processing, sedimentation and scavenging, which more strongly affect the accumulation and coarse size range.

In previous studies, we have assembled benchmark observational datasets against which to evaluate global aerosol microphysics models and to better understand the processes controlling the evolution of the particle size distribution in the atmosphere. Here, we have used these datasets to give context for the differences between the parametrized modal 
and more sophisticated sectional versions of the 3-D offline global aerosol microphysics model.

In this paper, we have refined the chosen values for the parameters inherent in a modal aerosol microphysics scheme to better compare with a sophisticated sectional scheme. By benchmarking the modal aerosol dynamics scheme against the bin scheme, we therefore reduce biases in simulated sizeresolved number concentrations and $\mathrm{CCN}$. In so doing, we aim to better constrain modal parameter settings and help improve predictions of aerosol properties and radiative forcings with two-moment modal schemes.

The bin and mode schemes perform similarly against observed $\mathrm{CN}$ and size-resolved particle concentration datasets in free troposphere, marine and continental regions. The simplification from bins to modes is found to be only a minor factor in determining the skill of the model against observations. We conclude therefore that the limitations in sizeresolved growth and removal in the modal approach cause only small biases in the model simulations, with the updated modal scheme general able to reproduce the global distribution of size-resolved particle concentrations only slightly worse than the sectional scheme.

In summary, the comparisons have shown that, in most parts of the atmosphere, bin-mode differences are less than model-observation differences, although some processes missing in these runs (e.g., boundary layer nucleation, ultrafine sea-spray) may well decrease the biases against observations stated here. However, the biases seen in the size distributions underline the need for a spectrum of complexity in global models, with size-resolved aerosol properties predicted by modal schemes needing to be continually benchmarked and improved against freely evolving sectional schemes and observations.

\section{Appendix A}

\section{Modifications to GLOMAP-mode compared to Mann et al. (2010)}

\section{A1 Vapour condensation}

The vapour condensation routine has been updated to use an improved representative size for the mode and to have revised calculation for the vapour diffusion coefficient $\left(D_{\mathrm{s}}\right)$. The "condensation sink radius" $\overline{r_{i, \text { cond }}}$ (see Lehtinen et al., 2003) is used when calculating the condensation coefficient whereas the geometric mean radius $\overline{r_{i, \mathrm{~g}}}$ was used in Mann et al. (2010). Lehtinen et al. (2003) explain that using $\overline{r_{i, \mathrm{~g}}}$ in monodisperse modal models (like GLOMAP-mode) will introduce biases which can become substantial in regions with high vapour condensation. They recommend instead using $\overline{r_{i, \text { cond }}}$, defined as the size giving the same condensation sink as the polydisperse distribution with corresponding $\overline{r_{i, \mathrm{~g}}}$. To evaluate $\overline{r_{i, \text { cond }}}$, one integrates the condensation sink ex- pression across the lognormally distributed particles, being essentially the 1 st moment mean radius in the continuum regime (small Knudsen number, large radius) and the 2nd moment mean radius in the molecular regime (large Knudsen number, small radius). For a lognormal mode with geometric standard deviation $\sigma$, the condensation sink radius is given by:

$\overline{r_{i, \text { cond }}}=\overline{r_{i}}\left(0.5 A^{2} \log ^{2} \sigma_{\mathrm{g}}\right)$

where $A$ is the "growth exponent" defined in Lehtinen et al. (2003). The condensation sink radius is evaluated with $A$ set to be 2.0, 1.9, 1.5 and 1.1 for nucleation, Aitken, accumulation and coarse modes, respectively. The new expression for $D_{\mathrm{s}}$ matches that implemented in GLOMAP-bin at v1a (e.g., Merikanto et al., 2009) following the approach of Fuller et al. (1966), using atomic diffusion volumes and a dependence on pressure and temperature (e.g., Poling et al., 2001). A further difference is that a minor bug was found which caused simulated nucleation rates to be slightly too high since gas phase $\mathrm{H}_{2} \mathrm{SO}_{4}$ was not being depleted for the (small) sink due to new particle formation.

\section{A2 Nucleation scavenging}

In the GLOMAP-mode approach in Mann et al. (2010), nucleation scavenging is applied only to soluble accumulation and soluble coarse modes. In the revised code here, we follow GLOMAP-bin in applying nucleation scavenging to soluble particles larger than a size threshold $r_{\text {scav }}$, the "scavenging radius". Also, in these runs, insoluble modes are scavenged in precipitating gridboxes where the temperature is below the ice frost point (taken to be $258 \mathrm{~K}$ ) to simulate removal as ice nuclei. This approach matches GLOMAP-bin, and leads to slightly reduced black carbon (BC) in the free troposphere compared to the simulations in Mann et al. (2010), where insoluble modes were not nucleation scavenged.

\section{A3 Aqueous sulphate production}

In Mann et al. (2010), the rate of aqueous phase sulphate production was calculated via an effective Henry's law approach. Here, we use a diffusion-limited approach, again to match GLOMAP-bin, whereby the sulphate production is limited by the rate of diffusion of $\mathrm{SO}_{2}$ to the cloud droplets. The gas-to-cloud-droplet transfer is calculated for each aerosol size class assuming cloud droplet radius is proportional to that of the aerosol particles (e.g., Spracklen et al., 2005).

\section{A4 Other differences in process settings}

Several process settings in the benchmark GLOMAP-bin run (B1) were different to those in the GLOMAP-mode version 5 run in Mann et al. (2010) ( $5_{\mathrm{M} 10}$ ). To make the bin and mode simulations consistent, we have changed 
Table A1. Summary of annual-mean concentrations of $\mathrm{SO}_{2}, \mathrm{H}_{2} \mathrm{SO}_{4}$, and mass of sulphate, EC, POM and sea-salt simulated by GLOMAPmode (improved configuration) with the ratio to that simulated by GLOMAP-bin shown in parentheses. Units for the GLOMAP-mode simulated values are $\mu \mathrm{g} \mathrm{S} \mathrm{m}^{-3}$ for $\mathrm{H}_{2} \mathrm{SO}_{4}, \mu \mathrm{g} \mathrm{S} \mathrm{m}{ }^{-3}$ for $\mathrm{SO}_{2}$ and $\mathrm{SO}_{4}, \mu \mathrm{g} \mathrm{C} \mathrm{m}{ }^{-3}$ for EC and POM and $\mu \mathrm{g} \mathrm{m}^{-3}$ for NaCl. Regions match those defined in Merikanto et al. (2009).

\begin{tabular}{lcccccc}
\hline Region & $\mathrm{SO}_{2}$ & $\mathrm{H}_{2} \mathrm{SO}_{4}$ & $\mathrm{SO}_{4}$ & $\mathrm{EC}$ & $\mathrm{POM}$ & $\mathrm{NaCl}$ \\
\hline Global & $0.17(0.90)$ & $0.025(0.82)$ & $0.30(0.93)$ & $0.07(0.88)$ & $0.42(0.85)$ & $6.48(0.92)$ \\
GloCnt & $0.40(0.89)$ & $0.032(0.79)$ & $0.47(0.91)$ & $0.18(0.86)$ & $1.07(0.82)$ & $0.45(1.17)$ \\
GloMrn & $0.08(0.92)$ & $0.027(0.84)$ & $0.23(0.94)$ & $0.03(0.94)$ & $0.17(0.93)$ & $8.82(0.91)$ \\
\hline Europe & $1.43(0.90)$ & $0.053(0.78)$ & $0.93(0.93)$ & $0.27(0.87)$ & $0.65(0.84)$ & $0.91(1.06)$ \\
Africa & $0.18(0.92)$ & $0.024(0.79)$ & $0.61(0.92)$ & $0.23(0.85)$ & $1.77(0.83)$ & $0.52(1.09)$ \\
N. Amer & $0.69(0.88)$ & $0.069(0.74)$ & $0.61(0.96)$ & $0.14(0.87)$ & $0.84(0.84)$ & $0.38(1.30)$ \\
S. Amer & $0.07(0.82)$ & $0.021(0.77)$ & $0.19(0.79)$ & $0.17(0.79)$ & $1.95(0.77)$ & $0.83(1.73)$ \\
N. Asia & $0.36(0.91)$ & $0.034(0.96)$ & $0.27(0.83)$ & $0.06(0.87)$ & $0.35(0.84)$ & $0.08(1.18)$ \\
SE. Asa & $1.17(0.88)$ & $0.039(0.69)$ & $1.07(0.95)$ & $0.51(0.89)$ & $1.43(0.87)$ & $0.32(1.40)$ \\
Oceana & $0.10(0.78)$ & $0.036(0.78)$ & $0.26(0.91)$ & $0.13(0.82)$ & $1.11(0.82)$ & $1.23(0.90)$ \\
\hline WofNAm & $0.03(0.93)$ & $0.010(0.78)$ & $0.23(0.93)$ & $0.02(1.15)$ & $0.10(1.09)$ & $8.04(0.85)$ \\
WofSAm & $0.02(0.92)$ & $0.013(0.74)$ & $0.19(0.96)$ & $0.01(1.01)$ & $0.06(0.93)$ & $8.41(0.79)$ \\
WofNAf & $0.13(0.96)$ & $0.056(0.88)$ & $0.36(0.94)$ & $0.02(1.00)$ & $0.09(0.99)$ & $9.14(0.89)$ \\
WofSAf & $0.03(0.96)$ & $0.014(0.84)$ & $0.25(0.89)$ & $0.08(0.88)$ & $0.63(0.87)$ & $8.44(0.81)$ \\
EoNEAs & $0.37(0.91)$ & $0.034(0.82)$ & $0.73(0.98)$ & $0.11(0.92)$ & $0.24(0.97)$ & $6.77(1.07)$ \\
\hline
\end{tabular}

Table A2. Summary of annual-mean CN (10 nm dry diameter), CCN (50 nm dry diameter), CCN (70 nm dry diameter), surface area density (dry) and condensation sink in the continuum region (dry) simulated by GLOMAP-mode (improved configuration) with the ratio to that simulated by GLOMAP-bin shown in parentheses. Units are $\mathrm{cm}^{-3}$ for $\mathrm{CN}$ and $\mathrm{CCN}, \mu \mathrm{m}^{2} \mathrm{~cm}^{-3}$ for surface area concentration and $\mu \mathrm{m} \mathrm{cm}-3$ for condensation sink. Regions match those defined in Merikanto et al. (2009).

\begin{tabular}{lccccc}
\hline Region & $\mathrm{CN}$ & $\mathrm{CCN}_{50}$ & $\mathrm{CCN}_{70}$ & sarea $_{\text {dry }}$ & csink $_{\text {cntm,dry }}$ \\
\hline Global & $766(1.11)$ & $534.1(1.18)$ & $450.2(1.17)$ & $494.2(0.99)$ & $5852(1.08)$ \\
GloCnt & $1717(1.13)$ & $1148.3(1.14)$ & $914.2(1.10)$ & $810.7(0.97)$ & $12141(1.07)$ \\
GloMrn & $396(1.07)$ & $295.4(1.25)$ & $269.9(1.27)$ & $371.3(1.00)$ & $3408(1.10)$ \\
\hline Europe & $3579(1.12)$ & $1830.9(1.13)$ & $1345.9(1.11)$ & $1136.5(0.99)$ & $20279(1.09)$ \\
Africa & $1516(1.18)$ & $1229.0(1.16)$ & $1072.4(1.13)$ & $1079.6(0.98)$ & $13645(1.09)$ \\
N.Amer & $1861(1.11)$ & $1247.8(1.16)$ & $934.0(1.10)$ & $803.2(0.96)$ & $12445(1.05)$ \\
S.Amer & $1572(1.08)$ & $1338.5(1.12)$ & $1141.4(1.09)$ & $951.9(0.90)$ & $13165(1.00)$ \\
N.Asia & $870(1.08)$ & $565.5(1.11)$ & $468.5(1.10)$ & $366.9(0.92)$ & $5830(1.02)$ \\
SE.Asa & $4666(1.16)$ & $2650.2(1.14)$ & $1921.3(1.08)$ & $1630.7(1.02)$ & $28308(1.12)$ \\
Oceana & $1158(1.07)$ & $968.2(1.11)$ & $816.3(1.12)$ & $685.8(0.95)$ & $9532(1.04)$ \\
\hline WofNAm & $427(1.08)$ & $345.4(1.41)$ & $327.8(1.42)$ & $360.2(1.00)$ & $3651(1.15)$ \\
WofSAm & $253(1.09)$ & $205.5(1.60)$ & $195.8(1.61)$ & $292.7(0.97)$ & $2378(1.22)$ \\
WofNAf & $404(1.04)$ & $317.0(1.29)$ & $301.0(1.31)$ & $426.6(0.99)$ & $3829(1.10)$ \\
WofSAf & $436(1.11)$ & $399.0(1.27)$ & $390.6(1.27)$ & $525.5(0.98)$ & $4810(1.13)$ \\
EoNEAs & $1365(1.08)$ & $899.4(1.11)$ & $775.7(1.13)$ & $754.5(1.01)$ & $9819(1.05)$ \\
\hline
\end{tabular}

several parameter settings in the GLOMAP-mode v6 runs here ( $v 6_{\mathrm{M} 12}$ ) compared to $\mathrm{v} 5_{\mathrm{M} 10}$, and these are listed here for completeness.

- Sea-salt emission dry radius range: $\mathrm{v}_{\mathrm{M} 10}$ emitted in the range $17.5 \mathrm{~nm}$ up to $14.4 \mu \mathrm{m}$, whereas $\mathrm{B} 1$ and $v 6_{\mathrm{M} 12}$ emit in the range $17.5 \mathrm{~nm}-7.0 \mu \mathrm{m}$. This explains why the sea-spray emission mass flux in $v 6_{\mathrm{M} 12}$ is a factor of three lower than at $\mathrm{v} 5_{\mathrm{M} 10}$.
- Condensation-ageing rate: v5 $5_{\mathrm{M} 10}$ used a 10 monolayer ageing rate where $\mathrm{B} 1$ and $\mathrm{v} 6_{\mathrm{M} 12}$ use 1 monolayer, leading to a shorter BC lifetime in $\mathrm{v} 6_{\mathrm{M} 12}$ than $\mathrm{v} 5_{\mathrm{M} 10}$.

- Activation dry diameter: at v $5_{\mathrm{M} 10}$ this minimum dry diameter for cloud processing was set to $75 \mathrm{~nm}$ whereas $\mathrm{B} 1$ and $\mathrm{v} 6_{\mathrm{M} 12}$ use $50 \mathrm{~nm}$. 
- Sticking efficiency for insoluble particles $\left(\mathrm{Se}_{\mathrm{ins}}\right)$ : at $v 5_{\mathrm{M} 10} \mathrm{Se}_{\mathrm{ins}}=0.3$, whereas B1 and $\mathrm{v} 6_{\mathrm{M} 12}$ have $\mathrm{Se}_{\mathrm{ins}}=$ 1.0 , as for soluble particles.

- Size distribution for primary carbonaceous emissions: v $5_{\mathrm{M} 10}$ used dry diameters of $60 \mathrm{~nm}$ for fossil fuels and $150 \mathrm{~nm}$ for biofuel/biomass burning sources and $\sigma=$ 1.59) (as in Stier et al., 2005) whereas $v 6_{\mathrm{M} 12}$ and B1 use $80 \mathrm{~nm}$ and $30 \mathrm{~nm}$ with $\sigma=1.8$ as recommended by AEROCOM (Dentener et al., 2006). Several papers (e.g., Spracklen et al., 2010) have shown that simulated particle concentrations are sensitive to the assumed size for primary emissions. Reddington et al. (2011) explore the sensitivity specifically around the Stier et al. (2005) and Dentener et al. (2006) values and find reduced bias against observations when the finer sizes are used.

Note also that where dust emissions and in-cloud sulphate production via $\mathrm{O}_{3}$ were included in $v 5_{\mathrm{M} 10}$, they are deactivated in $\mathrm{v}_{\mathrm{M} 12}$ since they were not included in B1.

One difference between B1, and GLOMAP-bin runs in most other papers, is that the nucleation scavenging wet radius $r_{\text {scav }}$ was set at $150 \mathrm{~nm}$, whereas it is usually set to $103 \mathrm{~nm}$. The rationale for changing $r_{\text {scav }}$ is from findings in Korhonen et al. (2008) where a low bias in GLOMAPbin simulated aerosol optical depth against observations was remedied when $r_{\text {scav }}$ was increased from 103 to $206 \mathrm{~nm}$. Also, we carried out three B1 simulations with $r_{\text {scav }}$ at 103 , 150 and at $200 \mathrm{~nm}$, and found $150 \mathrm{~nm}$ gave best agreement against the aircraft SP2 observations from Schwarz et al. (2010). Note that in GLOMAP-mode $v 6_{\mathrm{M} 12}, r_{\text {scav }}=$ $103 \mathrm{~nm}$. The different $r_{\text {scav }}$ values for bin and mode is considered appropriate since the size bins in GLOMAP-bin allow the process to cut off size distributions sharply at that size. By contrast, in GLOMAP-mode, the modal size classes are much wider (see Fig. 2), and follow a prescribed $\sigma$, so size distributions at the large-end of the accumulation mode will tail off gradually, according to the prescribed $\sigma$ for the mode.

\section{Appendix B}

\section{Summary of the bin-mode comparison in different regions}

Here, to clarify the extent of the bin-mode differences (which are only shown in broad terms in the figures), we tabulate regional mean values of the range of aerosol properties covered in the paper. Table A1 shows the values for the key precursor gases and each of the aerosol component masses, while Table A2 presents the numbers for $\mathrm{CN}, \mathrm{CCN}$ and moments of the aerosol size distribution. The first number shown is that simulated by GLOMAP-mode, with the bias compared to GLOMAP-bin shown in parentheses.
Acknowledgements. This work is supported by the Natural Environment Research Council (NERC) through the National Centre for Atmospheric Science. We acknowledge funding from the EU Framework Program 6 (FP6) project European Aerosol Cloud Climate and Air Quality Interactions (EUCAARI) and the FP7 projects Monitoring of Atmospheric Composition and Climate (MACC) and The Pan-European Gas Aerosol Climate Interaction Study (PEGASOS). We also acknowledge funding from NERC project AEROFORM (NE/D01395X/1), the NERC Directed Research Programme APPRAISE (Theme 3) and the NERC QUEST programme (Earth System Modelling). The development of UKCA is supported by both NERC and the DECC and Defra Integrated Climate Programme - DECC/Defra (GA01101). We also gratefully acknowledge AEROCOM and GEIA for providing emissions datasets, ISCCP for the monthly low cloud fields and ECMWF for the ERA40 reanalysis fields. We thank the scientists and data providers associated with the EMEP, CASTNET, IMPROVE and University of Miami networks. We also thank the data PIs for the $\mathrm{CN}$ and $\mathrm{CCN}$ surface measurements at the WMO-GAW sites (J. Ogren, NOAA, ESRL; J. Gras, CSIRO; U. Baltensberger, PSI; U. Kaminski, DWD; G. Jennings, NUI Galway; R. Weller, AWI; Y. Viisanen, FMI) for making their data available via the World Data Centre for Aerosols website. We are also grateful to F. O'Connor (UK Met Office Hadley Centre) for providing the TOMCAT oxidant fields.

Edited by: V.-M. Kerminen

\section{References}

Adams, P. J. and Seinfeld, J. H.: Predicting global aerosol size distributions in general circulation models, J. Geophys. Res., 107, 4370, doi:10.1029/2001JD001010, 2002.

Alexander, B., Park, R. J., Jacob, D. J., and Gong S.: Transition metal-catalyzed oxidation of atmospheric sulfur: Global implications for the sulfur budget, J. Geophys. Res., 114, D02309, doi:10.1029/2008JD010486, 2009.

Arnold, S., Chipperfield, M., and Blitz, M.: A three-dimensional model study of the effect of new temperature-dependent quantum yields for acetone photolysis, J. Geophys. Res., 110, D22305, doi:10.1029/2005JD005998, 2005.

Asmi, A., Wiedensohler, A., Laj, P., Fjaeraa, A.-M., Sellegri, K., Birmili, W., Weingartner, E., Baltensperger, U., Zdimal, V. Zikova, N., Putaud, J.-P., Marinoni, A., Tunved, P., Hansson, H.C., Fiebig, M., Kivekas, N., Lihavainen, H., Asmi, E., Ulevicius, V., Aalto, P. P., Swietlicki, E., Kristensson, A., Mihalopoulos, N. Kalivitis, N., Kalapov, I., Kiss, G., de Leeuw, G., Henzing, B., Harrison, R. M., Beddows, D., Dowd, C. O. Jennings, S. G., Flentje, H., Weinhold, K., Meinhardt, F., Ries, L., and Kulmala, M.: Number size distributions and seasonality of submicron particles in Europe 2008-2009, Atmos. Chem. Phys., 11, 5505-5538, doi:10.5194/acp-11-5505-2011, 2011.

Ayers, G. and Gras, J.: Seasonal relationship between cloud condensation nuclei and aerosol methanesulphonate in marine air, Nature, 353, 834-835, 1991.

Ayers, G., Ivey, J., and Gillett, R.: Coherence between seasonal cycles of dimethylsulfide, methanesulfonate, and sulfate in marine air, Nature, 349, 404-406, 1991. 
Bauer, S. E. and Koch, D.: Impact of heterogeneous sulfate formation at mineral dust surfaces on aerosol loads and radiative forcing in the Goddard Institute for Space Studies general circulation model, J. Geophys. Res., 110, D17202, doi:10.1029/2005JD005870, 2005.

Bauer, S. E., Wright, D. L., Koch, D., Lewis, E. R., McGraw, R., Chang, L.-S., Schwartz, S. E., and Ruedy, R.: MATRIX (Multiconfiguration Aerosol TRacker of mIXing state): an aerosol microphysical module for global atmospheric models, Atmos. Chem. Phys., 8, 6003-6035, doi:10.5194/acp-8-60032008, 2008.

Bergman, T., Kerminen, V.-M., Korhonen, H., Lehtinen, K. J., Makkonen, R., Arola, A., Mielonen, T., Romakkaniemi, S., Kulmala, M., and Kokkola, H.: Evaluation of the sectional aerosol microphysics module SALSA implementation in ECHAM5HAM aerosol-climate model, Geosci. Model Dev. Discuss., 4, 3623-3690, doi:10.5194/gmdd-4-3623-2011, 2011.

Birmili, W., Wiedensohler, A., Heintzenberg, J., and Lehmann, K.: Atmospheric particle number size distirbution in Central Europe: Statistical relations to air masses and meterology, J. Geophys. Res., 106, 32005-32018, 2001.

Carver, G. D. and Stott, P. A.: IMPACT: an implicit time integration scheme for chemical species and families, Ann. Geophys., 18, 337-346, doi:10.1007/s00585-000-0337-y, 2000.

Carver, G. D., Brown, P. D., and Wild, O.: The ASAD atmospheric chemistry integration package and chemical reaction database, Comp. Phys. Comm., 105, 197-215, 1997.

Chipperfield, M. P.: New version of the TOMCAT/SLIMCAT offline chemistry transport model, Q. J. Roy. Meteor. Soc., 132, 1179-1203, 2006.

Clarke, A. D.: Atmospheric nuclei in the Pacific Midtroposphere: their nature, concentration, and evolution, J. Geophys. Res., 98, 20633-20647, 1993.

Clarke, A. D. and Kapustin, V. N.: A Pacific aerosol survey. Part 1: A decade of data on particle production, transport, evolution and mixing in the troposphere, J. Atmos. Sci., 59, 363-382, 2002.

de Meij, A., Krol, M., Dentener, F., Vignati, E., Cuvelier, C., and Thunis, P.: The sensitivity of aerosol in Europe to two different emission inventories and temporal distribution of emissions, Atmos. Chem. Phys., 6, 4287-4309, doi:10.5194/acp-6-4287-2006, 2006.

Dentener, F., Kinne, S., Bond, T., Boucher, O., Cofala, J., Generoso, S., Ginoux, P., Gong, S., Hoelzemann, J. J., Ito, A., Marelli, L., Penner, J. E., Putaud, J.-P., Textor, C., Schulz, M., van der Werf, G. R., and Wilson, J.: Emissions of primary aerosol and precursor gases in the years 2000 and 1750 prescribed data-sets for AeroCom, Atmos. Chem. Phys., 6, 43214344, doi:10.5194/acp-6-4321-2006, 2006.

Easter, R. C., Ghan, S. J., Zhang, Y., Saylor, R. D., Chapman, E. G., Laulainen, N. S., Abdul-Razzak, H., Leung, R., Bian, X. and Zaveri, R. A.: MIRAGE: Model description and evaluation of aerosols and trace gases, J. Geophys. Res., 109, D20210, doi:10.1029/2004JD004571, 2004.

Forster, P., Ramaswamy, V., Artaxo, P., Berntsen, T., Betts, R., Fahey, D. W., Haywood, J., Lean, J., Lowe, D. C., Myhre, G., Nganga, J., Prinn, R., Raga, G., Schulz, M., and Van Dorland, R.: Climate change 2007: the physical science basis, in: Changes in Atmospheric Constituents and in Radiative Forcing, Contribution of Working Group I to the Fourth Assessment Report of the
Intergovernmental Panel on Climate Change, Cambridge University Press, Cambridge, New York, 129-234, 2007.

Fuller, E. N., Schetller, P. D., and Giddings, J. C.: A new method for the prediction of binary gas phase diffusion coefficients, Ind. Eng. Chem., 58, 5, 18-27, 1966.

Gelbard, F., Tambour, Y., and Seinfeld, J. H.: Sectional representations for simulating aerosol dynamics, J. Coll. Int. Sci., 76, 363382, 1980.

Ghan, S., Laulainen, N., Easter, R., Wagener, R., Nemesure, S., Chapman, E., Zhang, Y., and Leung, R.: Evaluation of aerosol direct radiative forcing in MIRAGE, J. Geophys. Res., 106, 52955316, 2001.

Ghan, S. J. and Schwartz, S. E.: Aerosol properties and processes: a path from field and laboratory measurements to global climate models, B. Am. Meteorol. Soc., 1059-1083, doi:10.1175/BAMS-88-7-1059, 2007.

Heintzenberg, J., Covert, D. C., and Van Dingenen, R.: Size distribution and chemical composition of marine aerosols: a compilation and review, Tellus B, 52, 1104-1122, 2000.

Herzog, M., Weisenstein, D. K., and Penner, J. E.: A dynamic aerosol module for global chemical transport models: Model description, J. Geophys. Res., 109, D18202, doi:10.1029/2003JD004405, 2004.

Hofmann, D. J.: Twenty years of balloon-borne tropospheric aerosol measurements at Laramie, Wyoming, J. Geophys. Res., 98, 12753-12776, 1993.

Holland, D. M., Principe. P. P., and Sickles II, J. E.: Trends in atmospheric sulfur and nitrogen species in the Eastern United States for 1989 to 1995, Atmos. Environ., 33, 37-49, 1999.

Hoppel, W. A., Frick, G. M., Fitzgerald, J. W., and Larson, R. E.: Marine boundary-layer measurements of new particle formation and the effects nonprecipitating clouds have on aerosol size distribution, J. Geophys. Res., 99, 14443-14459, 1994.

Holtslag, A. and Boville, B.: Local versus nonlocal boundary layer diffusion in a global climate model, J. Climate, 6, 1825-1842, 1993.

Johnson, C. E., Mann, G. W., Bellouin, N. O'Connor, F. M. and Dalvi, M.: Comparison between UKCA-MODE and CLASSIC aerosol schemes in HadGEM3, Integrated Climate Programme Deliverable M3.2, Report CR-ICP-2007-2012 to DECC, Defra \& MoD, available online at: http://www.ukca.ac.uk/wiki/images/ f/f8/ICP.pdf (last access: 18 February 2011) 2010.

Jones, A., Roberts, D. L., Woodage, M. J., and Johnson, C. E.: Indirect sulfate aerosol forcing in a climate model with an interactive sulfur cycle, J. Geophys. Res., 106, 20293-20310, 2001.

Jourdain, B. and Legrand, M.: Seasonal variations of atmospheric dimethylsulfide, dimethylsulfoxide, sulfur dioxide, methanesulfonate, and non-sea-salt sulfate aerosols at Dumont d'Urville (coastal Antartctica) (December 1998 to July 1999), J. Geophys. Res., 106, 14391-14408, 2001.

Kokkola, H., Korhonen, H., Lehtinen, K. E. J., Makkonen, R., Asmi, A., Järvenoja, S., Anttila, T., Partanen, A.-I., Kulmala, M., Järvinen, H., Laaksonen, A., and Kerminen, V.-M.: SALSA a Sectional Aerosol module for Large Scale Applications, Atmos. Chem. Phys., 8, 2469-2483, doi:10.5194/acp-8-2469-2008, 2008.

Kokkola, H., Hommel, R., Kazil, J., Niemeier, U., Partanen, A.-I., Feichter, J., and Timmreck, C.: Aerosol microphysics modules in the framework of the ECHAM5 climate model - intercomparison 
under stratospheric conditions, Geosci. Model Dev., 2, 97-112, doi:10.5194/gmd-2-97-2009, 2009.

Korhonen, H., Carslaw, K. S., Spracklen, D. V., Ridley, D. A., and Ström, J. : A global model study of processes controlling aerosol size distributions in the Arctic spring and summer, J. Geophys. Res., 113, D08211, doi:10.1029/2007JD009114, 2008.

Kulmala, M., Laaksonen, A., and Pirjola, L.: Parameterizations for sulfuric acid/water nucleation rates, J. Geophys. Res., 103, 83018307, 1998.

Kulmala, M., Vehkamäkki, H., Petäjä, T., Dal Maso, M., Lauri, A., Kerminen, V.-M., Birmili, W., and McMurry, P. H.: Formation and growth rates of ultrafine atmospheric particles: a review of observations, J. Aerosol Sci., 35, 143-176, 2004.

Kulmala, M., Asmi, A., Lappalainen, H. K., Baltensperger, U., Brenguier, J.-L., Facchini, M. C., Hansson, H.-C., Hov, Ø., O'Dowd, C. D., Pöschl, U., Wiedensohler, A., Boers, R., Boucher, O., de Leeuw, G., Denier van der Gon, H. A. C., Feichter, J., Krejci, R., Laj, P., Lihavainen, H., Lohmann, U., McFiggans, G., Mentel, T., Pilinis, C., Riipinen, I., Schulz, M., Stohl, A., Swietlicki, E., Vignati, E., Alves, C., Amann, M., Ammann, M., Arabas, S., Artaxo, P., Baars, H., Beddows, D. C. S., Bergström, R., Beukes, J. P., Bilde, M., Burkhart, J. F., Canonaco, F., Clegg, S. L., Coe, H., Crumeyrolle, S., D'Anna, B., Decesari, S., Gilardoni, S., Fischer, M., Fjaeraa, A. M., Fountoukis, C., George, C., Gomes, L., Halloran, P., Hamburger, T., Harrison, R. M., Herrmann, H., Hoffmann, T., Hoose, C., Hu, M., Hyvärinen, A., Hõrrak, U., Iinuma, Y., Iversen, T., Josipovic, M., Kanakidou, M., Kiendler-Scharr, A., Kirkevåg, A., Kiss, G., Klimont, Z., Kolmonen, P., Komppula, M., Kristjánsson, J.-E., Laakso, L., Laaksonen, A., Labonnote, L., Lanz, V. A., Lehtinen, K. E. J., Rizzo, L. V., Makkonen, R., Manninen, H. E., McMeeking, G., Merikanto, J., Minikin, A., Mirme, S., Morgan, W. T., Nemitz, E., O’Donnell, D., Panwar, T. S., Pawlowska, H., Petzold, A., Pienaar, J. J., Pio, C., Plass-Duelmer, C., Prévôt, A. S. H., Pryor, S., Reddington, C. L., Roberts, G., Rosenfeld, D., Schwarz, J., Seland, Ø., Sellegri, K., Shen, X. J., Shiraiwa, M., Siebert, H., Sierau, B., Simpson, D., Sun, J. Y., Topping, D., Tunved, P., Vaattovaara, P., Vakkari, V., Veefkind, J. P., Visschedijk, A., Vuollekoski, H., Vuolo, R., Wehner, B., Wildt, J., Woodward, S., Worsnop, D. R., van Zadelhoff, G.-J., Zardini, A. A., Zhang, K., van Zyl, P. G., Kerminen, V.-M., S Carslaw, K., and Pandis, S. N.: General overview: European Integrated project on Aerosol Cloud Climate and Air Quality interactions (EUCAARI) - integrating aerosol research from nano to global scales, Atmos. Chem. Phys., 11, 13061-13143, doi:10.5194/acp11-13061-2011, 2011.

Lauer, A., Hendricks, J., Ackermann, I., Schell, B., Hass, H., and Metzger, S.: Simulating aerosol microphysics with the ECHAM/MADE GCM - Part I: Model description and comparison with observations, Atmos. Chem. Phys., 5, 3251-3276, doi:10.5194/acp-5-3251-2005, 2005.

Lehtinen, K. E. J., Korhonen, H., Dal Maso, M., and Kulmala, M.: On the concept of condensation sink diameter, Boreal Environ. Res., 8, 405-411, 2003.

Liu, X., Penner, J. E., and Herzog, M.: Global modeling of aerosol dynamics: Model description, evaluation, and interactions between sulfate and nonsulfate aerosols, J. Geophys. Res., 110, D18206, doi:10.1029/2004JD005674, 2005.
Loevblad, G., Tarrason, L., and Torseth, K.: Sulphur, in: EMEP Assessment, Part 1: European Perspective, edited by: Loevblad, G., Tarrason, L., Torseth, K., and Dutchak, S., Norwegian Meteorol. Inst., Oslo, 15-46, 2004.

Luo, G. and Yu, F.: Sensitivity of global cloud condensation nuclei concentrations to primary sulfate emission parameterizations, Atmos. Chem. Phys., 11, 1949-1959, doi:10.5194/acp-111949-2011, 2011.

Makela, J. M., Aalto, P., Jokinen, V., Pohja, T., Nissinen, A., Palmroth, S., Markkanen, T., Seitsonen, K., Lihavainen, H., and Kulmala, M.: Observations of ultrafine aerosol particle formation and growth in boreal forest, Geophys. Res. Lett., 24, 1219-1222, 1997.

Malm, W. C., Schichtel, B. A., Ames, R. B., and Gebhart, K. A.: A 10-year spatial and temporal trend of sulfate across the United States, J. Geophys. Res., 107, 4627, doi:10.1029/2002JD002107, 2002.

Mann, G. W., Carslaw, K. S., Spracklen, D. V., Ridley, D. A., Manktelow, P. T., Chipperfield, M. P., Pickering, S. J., and Johnson, C. E.: Description and evaluation of GLOMAP-mode: a modal global aerosol microphysics model for the UKCA composition-climate model, Geosci. Model Dev., 3, 519-551, doi:10.5194/gmd-3-519-2010, 2010.

McGraw, R.: Description of Aerosol Dynamics by the Quadrature Method of Moments, Aerosol Sci. Technol., 27, 255-265, 1997.

Merikanto, J., Spracklen, D. V., Mann, G. W., Pickering, S. J., and Carslaw, K. S.: Impact of nucleation on global CCN, Atmos. Chem. Phys., 9, 8601-8616, doi:10.5194/acp-9-8601-2009, 2009.

Morgenstern, O., Braesicke, P., O’Connor, F. M., Bushell, A. C., Johnson, C. E., Osprey, S. M., and Pyle, J. A.: Evaluation of the new UKCA climate-composition model - Part 1: The stratosphere, Geosci. Model Dev., 2, 43-57, doi:10.5194/gmd-2-432009, 2009.

Nguyen, B., Mihalopoulos, N., Putaud, J., Gaudry, A. and Gallet, L.: Covariations in oceanic dimethyl sulfide, its oxidation products and rain acidity at Amsterdam Island in the Southern Indian Ocean, J. Atmos. Chem., 15, 39-53, 1992.

Penner, J. E., Andreae, M., Annegarn, H., Barrie, L., Feichter, J., Hegg, D., Jayaraman, A., Leaitch, R., Murphy, D., Nganga, J., and Pitari, G.: Aerosols, their direct and indirect effects, in: Climate Change 2001: The Scientific Basis. Contribution of Working Group I to the Third Assessment Report of the Intergovernmental Panel on Climate Change, edited by: Houghton, J. T., Ding, Y., Griggs, D. J., Noguer, M., van der Linden, P. J., Dai, X., Maskell, K., and Johnson, C. A., Cambridge University Press, Cambridge, New York, 289-348, 2001.

Petters, M. D. and Kreidenweis, S. M.: A single parameter representation of hygroscopic growth and cloud condensation nucleus activity, Atmos. Chem. Phys., 7, 1961-1971, doi:10.5194/acp-71961-2007, 2007.

Petzold, A., Fiebig, M., Flentje, H., Keil, A., Leiterer, U., Schroeder, F., Stifter A., Wendisch, M., and Wendling P.: Vertical variability of aerosol properties observed at a continental site during the Lindenberg Aerosol Characterization Experiment (LACE98), J. Geophys. Res., 107, 8128, doi:10.1029/2001JD001043, 2002.

Pirjola, L., Kulmala, M., Wilck, M., Bischoff, A., Stratmann, F., and Otto, E.: Formation of sulphuric acid aerosols and cloud 
condensation nuclei: An expression for significant nucleation and model comparison, J. Aerosol Sci., 30, 1079-1094, 1999.

Poling, B. E., Prausnitz, J. M., and O'Connell, J. P.: The properties of gases and liquids, McGraw-Hill, 768 pp., 2001.

Pringle, K. J., Tost, H., Metzger, S. Steil, B., Giannadaki, D., Nenes, A., Fontoukis, C., Stier, P., Vignati, E., and Lelieveld, J.: Description and evaluation of GMXe: a new aerosol submodel for global simulations (v1), Geosci. Model Dev., 3, 391-412, doi:10.5194/gmd-3-391-2010, 2010.

Raes, F.: Entrainment of free tropospheric aerosol as a regulating mechanism for cloud condensation nuclei in the remote marine boundary layer, J. Geophys. Res., 100, 2893-2903, 1995.

Raes, F., Van Dingenen, R., Vignati, E., Wilson, J., Putaud, J.-P., Seinfeld, J. H., and Adams, P.: Formation and cycling of aerosols in the global troposphere, Atmos. Environ., 34, 4215-4240, 2000.

Rasch, P. J., Feichter, J., Law, K., Mahowald, N., Penner, J., Benkowitz, C., Genthon, C., Giannakopoulos, C., Kasibhatla, P., Koch, D., Levy, H., Maki, T., Prather, M., Roberts, D. L., Roelofs, G.-J., Stevenson, D., Stockwell, Z., Taguchi, S., Kritz, M., Chipperfield, M., Baldocchi, D., McMurry, P., Barrie, L., Balkanski, Y., Chatfield, R., Kjellstrom, E., Lawrence, M., Lee, H. N., Lelieveld, J., Noone, K. J., Seinfeld, J., Stenchikov, G., Schwartz, S., Walcek, C., and Williamson, D.: A comparison of scavenging and deposition processes in global models: results from the WCRP Cambridge Workshop of 1995, Tellus B, 52, 1025-1056, 2000.

Reade, L., Jennings, S. G., and McSweeney, G.: Cloud condensation nuclei measurements at Mace Head, Ireland, over the period 1994-2002, Atmos. Res., 82, 610-621, 2006.

Reddington, C. L., Carslaw, K. S., Spracklen, D. V., Frontoso, M. G., Collins, L., Merikanto, J., Minikin, A., Hamburger, T., Coe, H., Kulmala, M., Aalto, P., Flentje, H., PlassDülmer, C., Birmili, W., Wiedensohler, A., Wehner, B., Tuch, T., Sonntag, A., O’Dowd, C. D., Jennings, S. G., Dupuy, R., Baltensperger, U., Weingartner, E., Hansson, H.-C., Tunved, P., Laj, P., Sellegri, K., Boulon, J., Putaud, J.-P., Gruening, C., Swietlicki, E., Roldin, P., Henzing, J. S., Moerman, M., Mihalopoulos, N., Kouvarakis, G., Ždímal, V., Zíková, N., Marinoni, A., Bonasoni, P., and Duchi, R.: Primary versus secondary contributions to particle number concentrations in the European boundary layer, Atmos. Chem. Phys., 11, 12007-12036, doi:10.5194/acp11-12007-2011, 2011.

Reddy, M. S., Boucher, O., Bellouin, N., Schulz, M., Balkanski, Y., Dufresne, J. L., and Pham, M.: Estimates of global multicomponent aerosol optical depth and direct radiative perturbation in the Laboratoire de Meteorologie Dynamique general circulation model, J. Geophys. Res., 110, D10S16, doi:10.1029/2004JD004757, 2005.

Rossow, W. and Schiffer, R.: Advances in understanding clouds from ISCCP, B. Am. Meteorol. Soc., 80, 2261-2287, 1999.

Schimel, D., Alves, D., Enting, I., Heimann, M., Joos, R., Raynaud, D., Wigley, T., Prather, M., Derwent, R., Ehhalt, D., Eraser, R., Sanhueza, E., Zhou, X., Jonas, R., Charlson, R., Rodhe, H., Sadasivan, S., Shine, K. R., Fouquart, Y., Ramaswamy, V., Solomon, S., Srinivasan, J., Albritton, D., Derwent, R., Isaksen, L., Lal, M., and Wuebbles, D.: Radiative forcing of climate change, in: Climate Change 1996, Contribution of Working Group I to the 2nd Assessment Report of the Intergovernmental Panel on Climate Change, edited by: Houghton, J. T.,
Meira Filho, L. G., Callander, B. A., Harris, N., Kattenberg, A., and Maskell, K., Cambridge University Press, Cambridge, New York, 1996.

Schwarz, J. P., Gao, R. S., Spackman, J. R., Watts, L. A., Thomson, D. S., Fahey, D. W., Ryerson, T. B., Peischl, J., Holloway, J. S., Trainer, M., Frost, G. J., Baynard, T., Lack, D. A., de Gouw, J. A., Warneke, C., and Del Negro, L. A.: Measurement of the mixing state, mass, and optical size of individual black carbon particles in urban and biomass burning emissions, Geophys Res. Lett., 35, L13810, doi:10.1029/2008GL033968, 2008.

Schwarz, J. P., Spackman, J. R., Gao, R. S., Watts, L. A., Stier, P., Schulz, M., Davis, S. M., Wofsy, S. C., and Fahey, D. W.: Global-scale black carbon profiles observed in the remote atmosphere and compared to models, Geophys. Res. Lett., 37, L18812, doi:10.1029/2010GL044372, 2010.

Seigneur, C., Hudischewskyj, A. B., Seinfeld, J. H., Whitby, K. T., Whitby, E. R., Brock, J. R., and Barnes, H. M.: Simulation of aerosol dynamics: a comparative review of mathematical models, Aerosol Sci. Technol., 5, 205-222, 1986.

Seinfeld, J. H. and Pandis, S. N.: Atmospheric Chemistry and Physics: From Air Pollution to Climate Change, WileyInterscience, 1326 pp., 1998.

Spracklen, D. V., Pringle, K. J., Carslaw, K. S., Chipperfield, M. P., and Mann, G. W.: A global off-line model of size-resolved aerosol microphysics: I. Model development and prediction of aerosol properties, Atmos. Chem. Phys., 5, 2227-2252, doi:10.5194/acp-5-2227-2005, 2005.

Spracklen, D. V., Carslaw, K. S., Kulmala, M., Kerminen, V.-M., Mann, G. W., and Sihto, S.-L.: The contribution of boundary layer nucleation events to total particle concentrations on regional and global scales, Atmos. Chem. Phys., 6, 5631-5648, doi:10.5194/acp-6-5631-2006, 2006.

Spracklen, D. V., Carslaw, K. S., Kulmala, M., Kerminen, V.-M., Sihto, S.-L., Riipinen, I., Merikanto, J., Mann, G. W., Chipperfield, M. P., Wiedensohler, A., Birmili, W., and Lihavainen, H.: Contribution of particle formation to global cloud condensation nuclei concentrations, Geophys. Res. Lett., 35, L06808, doi:10.1029/2007GL033038, 2008

Spracklen, D. V., Carslaw, K. S., Merikanto, J., Mann, G. W., Reddington, C. L., Pickering, S., Ogren, J. A., Andrews, E., Baltensperger, U., Weingartner, E., Boy, M., Kulmala, M., Laakso, L., Lihavainen, H., Kivekäs, N., Komppula, M., Mihalopoulos, N., Kouvarakis, G., Jennings, S. G., O’Dowd, C., Birmili, W., Wiedensohler, A., Weller, R., Gras, J., Laj, P., Sellegri, K., Bonn, B., Krejci, R., Laaksonen, A., Hamed, A., Minikin, A., Harrison, R. M., Talbot, R., and Sun, J.: Explaining global surface aerosol number concentrations in terms of primary emissions and particle formation, Atmos. Chem. Phys., 10, 4775-4793, doi:10.5194/acp-10-4775-2010, 2010.

Spracklen, D. V., Carslaw, K. S., Pöschl, U., Rap, A., and Forster, P. M.: Global cloud condensation nuclei influenced by carbonaceous combustion aerosol, Atmos. Chem. Phys., 11, 9067-9087, doi:10.5194/acp-11-9067-2011, 2011.

Stier, P., Feichter, J., Kinne, S., Kloster, S., Vignati, E., Wilson, J., Ganzeveld, L., Tegen, I., Werner, M., Balkanski, Y., Schulz, M., Boucher, O., Minikin, A., and Petzold, A.: The aerosol-climate model ECHAM5-HAM, Atmos. Chem. Phys., 5, 1125-1156, doi:10.5194/acp-5-1125-2005, 2005. 
Taylor, K. E.: Summarizing multiple aspects of model performance in a single diagram, J. Geophys. Res., 106, 7183-7192, 2001.

Telford, P., Braesicke, P., Morgenstern, O., and Pyle, J.: Reassessment of causes of ozone column variability following the eruption of Mount Pinatubo using a nudged CCM, Atmos. Chem. Phys., 9, 4251-4260, doi:10.5194/acp-9-4251-2009, 2009.

Textor, C., Schulz, M., Guibert, S., Kinne, S., Balkanski, Y., Bauer, S., Berntsen, T., Berglen, T., Boucher, O., Chin, M., Dentener, F., Diehl, T., Easter, R., Feichter, H., Fillmore, D., Ghan, S., Ginoux, P., Gong, S., Grini, A., Hendricks, J., Horowitz, L., Huang, P., Isaksen, I., Iversen, I., Kloster, S., Koch, D., Kirkevåg, A., Kristjansson, J. E., Krol, M., Lauer, A., Lamarque, J. F., Liu, X., Montanaro, V., Myhre, G., Penner, J., Pitari, G., Reddy, S., Seland, Ø., Stier, P., Takemura, T., and Tie, X.: Analysis and quantification of the diversities of aerosol life cycles within AeroCom, Atmos. Chem. Phys., 6, 1777-1813, doi:10.5194/acp-6-1777-2006, 2006.

Tiedtke, M.: A comprehensive mass flux scheme for cumulus parameterization in large-scale models, Mon. Weather Rev., 117, 1779-1800, 1989.

Trivitayanurak, W., Adams, P. J., Spracklen, D. V., and Carslaw, K. S.: Tropospheric aerosol microphysics simulation with assimilated meteorology: model description and intermodel comparison, Atmos. Chem. Phys., 8, 3149-3168, doi:10.5194/acp-8-3149-2008, 2008.

Vignati, E., Wilson, J., and Stier, P.: M7: An efficient size-resolved aerosol microphysics module for large-scale aerosol transport models, J. Geophys. Res., 109, D22202, doi:10.1029/2003JD004485, 2004.
Vignati, E., Karl, M., Krol, M., Wilson, J., Stier, P., and Cavalli, F.: Sources of uncertainties in modelling black carbon at the global scale, Atmos. Chem. Phys., 10, 2595-2611, doi:10.5194/acp-102595-2010, 2010.

Weisenstein, D. K., Penner, J. E., Herzog, M., and Liu, X.: Global 2$\mathrm{D}$ intercomparison of sectional and modal aerosol modules, Atmos. Chem. Phys., 7, 2339-2355, doi:10.5194/acp-7-2339-2007, 2007.

Whitby, K. T.: The physical characteristics of sulfur aerosols, Atmos. Environ., 12, 135-159, 1978.

Whitby, K. T.: Determination of aerosol growth rates in the atmosphere using lumped mode aerosol dynamics, J. Aerosol Sci., 12, 173-178, 1981.

Wilson, J., Cuvelier, C., and Raes, F.: A modeling study of global mixed aerosol fields, J. Geophys. Res., 106, 34081-34108, 2001.

Zhang, Y., Seigneur, C., Seinfeld, J. H., and Jacobson, M. Z.: Simulation of aerosol dynamics: a comparative review of algorithms used in air quality models, Aerosol Sci. Technol., 31, 487-514, 1999.

Zhang, K., Wan, H., Wang, B., Zhang, M., Feichter, J., and Liu, X.: Tropospheric aerosol size distributions simulated by three online global aerosol models using the M7 microphysics module, Atmos. Chem. Phys., 10, 6409-6434, doi:10.5194/acp-10-64092010, 2010. 